\title{
Influence of Annealing Temperature on the Morphology and the Supercapacitance Behavior of Iron Oxide Nanotube (Fe-NT)
}

\author{
Biplab Sarma $^{\mathrm{a}}$, Abraham L. Jurovitzki ${ }^{\mathrm{a}}$, York R. Smith ${ }^{\mathrm{a}}$, Rupashree S. Ray ${ }^{\mathrm{a}}$, and Mano Misra ${ }^{\mathrm{a}, \mathrm{b}, 1}$ \\ ${ }^{a}$ Metallurgical Engineering Department, University of Utah, Salt Lake City, UT 84112, USA \\ ${ }^{\mathrm{b}}$ Chemical Engineering Department, University of Utah, Salt Lake City, UT 84112, USA \\ Keywords: Iron oxide Nanotube, electrochemical supercapacitor, charge-discharge, Annealing,
}

Pseudocapacitance

\begin{abstract}
The article demonstrates the influence of annealing temperature on the supercapacitance behavior of iron oxide nanotube synthesized on pure iron substrate by electrochemical anodization process. Anodization was performed in an ethylene glycol solution containing 3\% $\mathrm{H}_{2} \mathrm{O}$ and 0.5 wt. $\% \mathrm{NH}_{4} \mathrm{~F}$. The as-anodized nanotubes were annealed in an ambient atmosphere at various temperatures ranging from 200 to $700^{\circ} \mathrm{C}$ for a fixed duration of time (2hrs). The morphology and crystal phases developed after anodization and subsequent annealing processes were examined using field emission scanning electron microscopy (FE-SEM), X-ray diffraction (XRD) and X-ray photospectroscopy (XPS). Cyclic voltammetry (CV), galvanostatic charge/discharge and electrochemical impedance spectroscopy (EIS) experiments were performed in $1 \mathrm{M} \mathrm{Li}_{2} \mathrm{SO}_{4}$ to evaluate the electrochemical capacitance properties of the oxide nanotube electrodes. It was found that the electrode annealed at $300^{\circ} \mathrm{C}$ exhibited superior electrochemical capacitance compared to the electrodes annealed at other temperatures. The highest specific capacitance achieved after annealing at $300^{\circ} \mathrm{C}$ was about $314 \mathrm{mF} \mathrm{cm}^{-2}$. The

\footnotetext{
${ }^{1}$ Corresponding author: mano.misra@utah.edu, Ph: 801-573-5614
} 
electrodes annealed at $200,500,600$ and $700^{\circ} \mathrm{C}$ displayed much lower specific capacitance compared to those annealed at 300 and $400^{\circ} \mathrm{C}$. Galvanostatic charge-discharge experiments conducted on some of the annealed electrodes demonstrated excellent cycle stability with more than $80 \%$ capacitance retention after 1000 charge-discharge cycles.

\section{Introduction}

Recent advancements in the fabrication and design of nanomaterials have pushed the research and developmental efforts in preparing efficient and economical energy storage devices. Among these devices, electrochemical capacitors (EC) are developed with an emphasis to attain high reversible power and energy density [1]. Based on the nature of electrochemical response, ECs are divided in to two categories, electric double layer (EDL) and pseudocapacitor [2]. The energy storage in the EDL capacitor relies on ion adsorption, while fast surface redox reactions are the primary mechanism for capacitance in pseudocapacitors [2]. However, it has also been reported that overall capacitance of an electrode can be a mixture of pseudocapacitance as well as EDL capacitance, thereby providing higher energy density than a pure EDL or pseudocapacitor alone $[3,4]$. Owing to high surface area, carbon based materials (i.e., charcoal, or carbon aerogel) exhibit high ELD capacitance; however, they are prone to degradation upon longer exposure to the electrolyte [5]. Numerous studies have been conducted to evaluate the electrochemical capacitance of transition metal oxides, such as $\mathrm{Ru}, \mathrm{Ni}, \mathrm{Co}$, and $\mathrm{Mn}$ [6-10]. Generally it was suggested that these metal can undergo several redox transitions because of their multiple valence states thereby resulting in enhanced pseudocapacitance behavior [10].

Among transition metal oxides, iron oxide exhibits many advantages, such as abundance, low-cost, non-toxicity and environmentally benign nature making it a promising electrode 
material for EC application. Consequently, a number of studies were performed to evaluate iron oxide for supercapacitance applications [11-19]. Wang et al. [11] conducted a detailed investigation of the capacitance mechanisms of a magnetite $\left(\mathrm{Fe}_{3} \mathrm{O}_{4}\right)$ electrode in various electrolytes, such as $\mathrm{Na}_{2} \mathrm{SO}_{3}, \mathrm{Na}_{2} \mathrm{SO}_{4}$, and $\mathrm{KOH}$. Their results suggested that the capacitance behavior of the $\mathrm{Fe}_{3} \mathrm{O}_{4}$ film in $\mathrm{Na}_{2} \mathrm{SO}_{3}$ originated from combined behavior of electric double layer (EDL) and pseudocapacitance while in $\mathrm{Na}_{2} \mathrm{SO}_{4}$, the current responses were found to be entirely due to EDL type behavior. A porous flower-like $\mathrm{Fe}_{2} \mathrm{O}_{3}$ nanostructured electrode prepared by Shivakumara et al. [18] exhibited a specific capacitance of $127 \mathrm{~F} \mathrm{~g}^{-1}$ in $\mathrm{Na}_{2} \mathrm{SO}_{3}$ electrolyte. They also attributed the capacitance to be a combination of EDL and pseudo-type behavior. In a different study, Binitha and co-workers [19] evaluated EC properties of nanostructured $\mathrm{Fe}_{2} \mathrm{O}_{3}$ electrodes prepared by electrospinning technique. The electrode underwent surface redox reactions culminating in a high specific capacitance of $\sim 256 \mathrm{~F} \mathrm{~g}^{-1}$ in $\mathrm{LiOH}$ electrolyte.

Nanostructured iron oxides have been synthesized using a number of fabrication methods, such as chemical precipitation, sol-gel, thermal decomposition, hydrothermal, template based, electrospinning and electrochemical anodization [20]. Among these methods, electrochemical anodization is a robust technique to produce nanotubular oxide layer on various valve metals (Al, Ti, Hf, Zr, Nb, W, and Ti [21-30]) with high control. Anodization has also been employed recently to produce nanotubular oxide layer on pure iron substrate [4, 31-33]. For instance, Xie et al. [4] studied the supercapacitance behavior of iron oxide electrode prepared by electrochemical anodization. They observed a specific capacitance of $138 \mathrm{~F} \mathrm{~g}^{-1}$ in their electrode. They concluded that the capacitance performance of their electrode was comparable to the values achieved in other transition metal oxide based supercapacitor materials. The superior capacitance of the Fe-oxide electrode was attributed to the nanotubular morphology 
with enhanced specific surface area, as well as the rapid and efficient mass/charge transfer through the tubular tunnels.

Following these discussions, this work evaluates the effect of annealing temperature on the supercapacitance properties of nanotubular iron oxide electrodes. It has been envisaged that annealing at various temperatures may induce changes in terms of the morphology, crystal-phase and intrinsic/bulk properties of the Fe-oxide nanotube-these aspects have not been studied well to the best of the author's knowledge. Further, such changes in the morphologies/properties could potentially impact the supecapacitance behavior of the electrode. Also, it is quite apparent from a quick overview of the literature that a detailed study encompassing the effect of annealing temperature on the supercapacitance behavior of iron oxide is still missing. Therefore, Fe-oxide nanotube electrodes were synthesized by electrochemical anodization of pure iron substrate. Subsequently, oxide electrodes were annealed in the ambient atmosphere at various temperatures, ranging from 200 to $700^{\circ} \mathrm{C}$ to study the influence of annealing on its supercapacitance properties in a much comprehensive manner. It was indeed observed that the supercapacitance behavior of the electrode was highly dependent on the annealing temperature and therefore, the finding of this research can potentially add much more to the existing literature for this particular domain.

\section{Experimental}

\subsection{Sample Preparation}

Iron foil (99.9\% pure) of $0.1 \mathrm{~mm}$ thickness was cut into $10 \mathrm{~mm}$ x $15 \mathrm{~mm}$ coupons. The coupons were polished and cleaned/degreased ultrasonically in a 50/50 (Vol.\%) solution of 
acetone and isopropyl alcohol for fifteen minutes. Afterwards, the coupons were air dried at $100^{\circ} \mathrm{C}$ using a laboratory oven.

\subsection{Potentiostatic Anodization}

Anodization was performed in a jacketed reactor connected to an enclosed water bath. The electrolyte was consisted of ethylene glycol (EG) with 0.5 wt \% ammonium fluoride $\left(\mathrm{NH}_{4} \mathrm{~F}\right)$ and $3 \% \mathrm{H}_{2} \mathrm{O}$. The anodization system consisted of a DC power source (Agilent Technologies, E3647A) connected to an iron coupon anode and a platinum cathode of similar dimensions. The electrolyte was stirred at $90 \mathrm{rpm}$ throughout the anodization. The anodization was carried out at a constant voltage of $50 \mathrm{~V}$ for 30 minutes. The temperature of the electrolyte bath was maintained $15^{\circ} \mathrm{C}$ throughout the experiments. Immediately, after anodization, the coupon was removed and ultrasonically cleaned for 3-5 seconds in DI water followed by drying under vacuum at $100^{\circ} \mathrm{C}$.

\subsection{Annealing}

Annealing of the nanotubes was performed at various temperatures: 200, 300, 400, 500, 600 , and $700^{\circ} \mathrm{C}$ in air environment. The temperature was raised at a rate of $5^{\circ} \mathrm{C} / \mathrm{min}$ to each of the set points and maintained for 2 hours followed by natural convection cooling. For clarity in further discussions, the Fe-NT electrodes annealed at a particular temperature is designated as Fe-NT-annealing temperature (e.g., Fe-NT-200 represents the electrode annealed at $200^{\circ} \mathrm{C}$ ).

\subsection{Characterization}

The morphological aspects of the anodized iron oxide nanotube were examined using a field emission scanning electron microscope (FE-SEM, Hitachi S-4800). The crystal phases and the surface composition of the nanotubes were examined by X-ray diffraction (XRD) and X-ray 
photoelectron spectroscopy (XPS). The XRD analysis of the samples was carried out using SIEMENS D5000 diffractometer with copper K- $\alpha$ radiation. The diffraction tests were done by $\theta$ to $\theta$ scan from $20^{\circ}$ to $80^{\circ}$. X-ray photoelectron spectroscopy (XPS) study was carried out using monochromatic Al Ka source $(\mathrm{PE}=1600 \mathrm{eV})$ on a Kratos Axis Ultra DLD instrument, with a $300-700 \mu \mathrm{m}$ spot size. Dwell time was set to $200 \mathrm{~ms}$ with three sweeps and a step size of $1 \mathrm{eV}$ (0.1 eV for regional scans). The surface areas of the Fe-NT material was evaluated using a Brunauer-Emmett-Teller (BET) using a Micromeritics ASAP 2020 analyzer after the sample was degassed in vacuum at $200^{\circ} \mathrm{C}$ for 3 hours. The surface area was determined by $\mathrm{N}_{2}$ adsorption/desorption isotherms at $-196^{\circ} \mathrm{C}$.

The electrochemical tests such as cyclic voltammetry, constant current charge-discharge and electrochemical impedance spectroscopy (EIS) were carried out in a three-electrode configuration with Fe-NT electrode as the anode, platinum foil as cathode, and $\mathrm{Ag} / \mathrm{AgCl}$ (3 M $\mathrm{KCl}$ ) as the reference electrode. All electrochemical test potentials are with respect to the reference electrode unless otherwise specified. The electrolyte was an aqueous solution of $1.0 \mathrm{M}$ $\mathrm{Li}_{2} \mathrm{SO}_{4}(\mathrm{pH} \sim 8)$. A computer-controlled potentiostat (Gamery-600) was used to control the potential and current during the experiments.

\section{Results and Discussion}

Figure 1 shows the top surface of the as-anodized (without anneal) nanotube layer depicting the self-organized and vertically aligned nature of the iron oxide nanotube (Fe-NT) structures formed after anodization at $50 \mathrm{~V}$ for 30 minutes. The inset shows the cross sectional view of the tubular arrays. The diameter and the wall thicknesses of the tubes were in the range of 80-100 nm and 25-30 nm, respectively, while the length was about $3.7 \mu \mathrm{m}$ (inset Fig. 1). The 
surface area of the Fe-NT material was estimated from BET analysis and was found to be 41.41 $\mathrm{m}^{2} \mathrm{~g}^{-1}$

The effect of the annealing temperature on the morphology of the Fe-NT is shown in Figures 2 and 3. The nanotubes were appeared to be stable, well connected, uniformly ordered after calcination at 200,300 and $400^{\circ} \mathrm{C}$ (Fig. 2(a-c)). There were no discernible changes in tube diameter and wall thickness upon annealing at these temperatures. However, when the annealing temperature was raised to $500^{\circ} \mathrm{C}$, slight distortion/disorderliness of the self-organized nanotube arrays can be observed from the SEM micrograph (Fig. 2d). Nevertheless, the nanotubular architecture was still retained with reasonable integrity at this temperature. However, the nanotubes were completely collapsed and changed to a nanorod (NR) structure when temperature was further raised to 600 and $700^{\circ} \mathrm{C}$. Figures $2(\mathrm{e}, \mathrm{f})$ shows the NR morphology of the oxide layer after annealing at $600^{\circ} \mathrm{C}$ - the inset image in Figure 2(f) suggested that the sizes of the NR were between 50 and $70 \mathrm{~nm}$. It appeared from these micrographs that the entire length of the nanotube was changed to NR. Further increase in annealing temperature to $700^{\circ} \mathrm{C}$ resulted in even more drastic changes in the morphology of the oxide layer (Fig. 3). While the NR morphology was still visible in certain areas, the evolution of whisker morphology of the oxide phase was also observed. However, it appears that the size of the NR did not change upon increase in annealing temperature from 600 to $700^{\circ} \mathrm{C}$. It is to be noted that in many nanostructured materials, such as $\mathrm{TiO}_{2}, \mathrm{MoO}_{3}$, and $\mathrm{NiO}$, high temperature thermal treatment results in the transformation from nanotube (NT) to NR morphology [34]. The mechanistic approach of how this transformation is brought about has been studied in depth for $\mathrm{TiO}_{2}$ based nanotube materials (T-NT) [35-37]. In the case of T-NT, it has been argued that the transformation from NT to NR is primarily due to the continual dehydration of the interlayered $\mathrm{OH}$ groups [35-37]. The dehydration process tends 
to decrease the inter-distance between Ti atoms which could impact the overall morphology of the nanostructure in two ways. First, the decrease in the inter-distance of the Ti atoms perpendicular to the tube direction leads to the collapse of the NT to NR morphology [35-37]. Secondly, decrease in the inter-distance of the Ti atoms along the tube axis results in a decrease in length, thereby forming shorter NR (compared to initial NT) after transformation [36,37]. In case of Fe-NT, a similar mechanism might be operative when the temperature was increased beyond $600^{\circ} \mathrm{C}$. In fact, it was observed that the length of the resultant $\mathrm{Fe}-\mathrm{NR}$ formed at $600^{\circ} \mathrm{C}$ was about $3 \mu \mathrm{m}$ (Fig. 2f), relatively shorter than the length of the NT that formed upon anodization (3.7 $\mu \mathrm{m}$, see Fig. 1). This decrease may have been due to the dehydration of the $\mathrm{OH}$ groups in Fe-NT layer, as observed in the case of T-NT. Nevertheless, based on the foregoing discussion, it becomes evident that to retain the nanotubular morphology, the annealing temperature shall not be more than $500^{\circ} \mathrm{C}$.

The Fe-NT oxide phase compositions were analyzed by XRD and X-ray photoelectron spectroscopy (XPS) techniques. Generally, anodization of transition metals such as iron, produces an oxide layer that is amorphous in nature, and becomes crystalline upon annealing $[4,32,33]$. The XRD profiles for the anodized iron oxide samples annealed at various temperatures are shown in Figure 4. At all annealing temperatures, the XRD peaks were sharp suggesting good crystallinity of the nanotube phases. The diffraction peaks observed from the (012), (104) and (110) planes appeared to be the strongest suggesting the dominance of the $\alpha$ $\mathrm{Fe}_{2} \mathrm{O}_{3}$ phase at all annealing temperatures. The other prominent peaks include: (024), (116), (018), (300) also correspond well with the $\mathrm{Fe}_{2} \mathrm{O}_{3}$ phase $[19,20]$. The peak observed from the (220) plane suggested the formation of small amount magnetite $\left(\mathrm{Fe}_{3} \mathrm{O}_{4}\right)$ in all samples. However, the intensity of this peak appeared to be decreased at higher temperatures, especially for samples 
annealed at 600 and $700^{\circ} \mathrm{C}$. This might be because of the fact that formation of $\mathrm{Fe}_{2} \mathrm{O}_{3}$ is favored over $\mathrm{Fe}_{3} \mathrm{O}_{4}$ phase at high temperatures [38]. Further, for the sample annealed at $700^{\circ} \mathrm{C}$, the $(110)$ reflections split into two peaks (Fig. 4). This peak splitting appeared to be due to hexagonal distortion of the lattice structure of hematite or might be due to the imposing compressive stress on the surface of the oxide layer by the increasing oxygen content at high temperature [39].

To further investigate the phase formation, XPS analysis was carried out on the Fe-NT electrodes. For this purpose, electrodes annealed at 300 and $400^{\circ} \mathrm{C}$ (Fe-NT-300 and Fe-NT-400) were selected as it would be evident from the electrochemical test results (vide infra) that these samples demonstrated superior supercapacitance properties compared to the other electrodes. The survey spectra for Fe-NT-300 and Fe-NT-400 electrodes showing both Fe2p and O1s peaks are presented in Figure 5(a). Figure 5(b) shows the XPS peaks of Fe $2 p_{3 / 2}$ and Fe $2 p_{1 / 2}$ for these samples. The profiles appear to be quite similar for both samples, strongly indicating the formation of predominantly $\mathrm{Fe}_{2} \mathrm{O}_{3}$ phase in both samples. This finding is also consistent with the results obtained from the XRD analysis for these samples (Fig. 4). Of the two peaks, Fe 2 $\mathrm{p}_{3 / 2}$ peak is narrower and stronger (greater intensity) than $\mathrm{Fe} 2 \mathrm{p}_{1 / 2}$. Moreover, the area of Fe $2 \mathrm{p}_{3 / 2}$ peak is greater than that of $F e 2 p_{1 / 2}$ as a result of the spin-orbit $(j-j)$ coupling; $F e ~ 2 p_{3 / 2}$ has degeneracy of four states whilst Fe $2 p_{1 / 2}$ has only two. The peak position of Fe $2 p_{3 / 2}$ has been investigated in many studies and the values ranges between 710.6-711.2 eV [40-43]. The Fe $2 \mathrm{p}_{3 / 2}$ peak has an associated satellite peak. The satellite peak of $\mathrm{Fe} 2 \mathrm{p}_{3 / 2}$ for $\mathrm{Fe}_{2} \mathrm{O}_{3}$ is located approximately $8 \mathrm{eV}$ higher than the main $\mathrm{Fe} 2 \mathrm{p}_{3 / 2}$ peak [41-43]. The satellite peak obtained at $718.5 \mathrm{eV}$ is clearly distinguishable and does not overlap either with the Fe $2 \mathrm{p}_{3 / 2}$ or Fe $2 \mathrm{p}_{1 / 2}$ peaks. The O1s spectra for these samples are shown in Fig 5(c). The peak located at $\sim 530.3 \mathrm{eV}$ corresponds to $\mathrm{O}^{2-}$ in the iron oxide lattice. Overall, the XPS analysis also indicated the 
formation of predominantly $\mathrm{Fe}_{2} \mathrm{O}_{3}$ phase in the $\mathrm{Fe}-\mathrm{NT}$ electrodes supporting well the XRD results (Fig. 4)

The supercapacitance properties of the Fe-NT electrodes were first evaluated by conducting $\mathrm{CV}$ experiments in an aqueous solution of $1 \mathrm{M} \mathrm{Li}_{2} \mathrm{SO}_{4}$ electrolyte in the potential window of 0 to $-0.8 \mathrm{~V}$. The results of this investigation are presented in Figure 6(a) \& inset figure with current-voltage responses for Fe-NT electrodes annealed at various temperatures. The $\mathrm{CV}$ experiments were carried out at a scan rate of $100 \mathrm{mV} \mathrm{s}^{-1}$. It is to be noted that in most annealing conditions, the $\mathrm{CV}$ profiles for the Fe-NT electrodes suggested a mixed electric double layer (EDL) and pseudo-type aspects of capacitance behavior. Similar supercapacitance behavior for Fe oxide electrode has been reported in some of the previous studies [2,44]. In our case, the CV profiles for the Fe-NT-400 and Fe-NT-500 electrodes displayed near rectangular shape (Fig. 6a and inset figure) indicative of the dominance of EDL type capacitance behavior for these electrodes. The $\mathrm{CV}$ profiles for these two electrodes exhibit reasonably rapid current reversals at each potential limit [2]. Therefore, it is reasonable to assume that the capacitance of the Fe-NT400 and Fe-NT-500 electrodes was dominated by the EDL type behavior due to charge storage at the electrode/electrolyte interface. The near rectangular behavior of the $\mathrm{CV}$ curves have also been observed for iron oxide electrodes in earlier studies and reported to be due to the part ELD type nature of the electrodes $[2,18,20,44]$. At a lower annealing temperature, especially at $300^{\circ} \mathrm{C}$, the electrode exhibited much higher supercapacitance compared to those annealed at 400 and $500^{\circ} \mathrm{C}$. This can easily be observed from the CV profile for the Fe-NT-300 electrode in Figure 6(a). The shape of the $\mathrm{CV}$ profile has also changed to ellipsoidal type from a near rectangular curved obtained for those Fe-NT-400 and Fe-NT-500 electrodes. A further decrease in the annealing temperature to $200^{\circ} \mathrm{C}$ reduced the specific capacitance as demonstrated by a 
smaller enclosed CV area (inset Fig. 6a). This may be partly due to lower electronic conductivity of the electrode [32]. On the other hand, increase in annealing temperature to 600 and $700^{\circ} \mathrm{C}$ also resulted in much lower supercapacitance properties of the electrodes. This was expected because of the distorted morphology of the nanostructures electrode after annealing at these temperatures (inset Fig. 6a). The nanotubular structure of the electrode was transformed to a NR structure at these temperatures which might have caused less efficient electrolytic flows during the $\mathrm{CV}$, resulting in lower current response for these electrodes.

The fundamental mechanism of charge transfer/redox processes involved in iron oxide electrode are not yet explored fully [11, 12]. Various aqueous based electrolytes, such as $\mathrm{Na}_{2} \mathrm{SO}_{3}, \mathrm{Na}_{2} \mathrm{SO}_{4}, \mathrm{Li}_{2} \mathrm{SO}_{4}, \mathrm{KOH}, \mathrm{NaOH}$, and $\mathrm{NaCl}$ etc. have been used to study the capacitance behavior of iron oxide electrodes [4, 11-19]. In most of these studies, it was found that the capacitance of iron oxide was partly due to the EDL at the electrode/electrolyte interface and also through the charge storage by redox reactions on the surface of the host material. In the case of the $\mathrm{Li}_{2} \mathrm{SO}_{4}$ electrolyte also, a mixed capacitance comprising of EDL as well as pseodocapacitance has been observed [3,4]. The pesudocapacitance nature of the electrode is the result from the charge storage in the host material through redox reactions on the surface of the electrode. The interaction of the $\mathrm{Fe}^{3+}$ ions with the $\mathrm{Li}_{2} \mathrm{SO}_{4}$ electrolyte where the intercalation and deintercalation of the $\mathrm{Li}^{+}$ionic species occurs through the tunnels and holes present in the crystal structure of the oxide phase has been suggested the underlying mechanism for the pseudocapacitance behavior [45]. From the CV profiles in Figure 6(a), two shallow and broad redox humps can be observed at $-0.2 \mathrm{~V}$ (anodic) and $-0.5 \mathrm{~V}$ (cathodic) for the Fe-NT-300 electrode. Similarly, the anodic and cathodic peaks for the Fe-NT-400 and Fe-NT-500 electrodes were observed to be between -0.2 to $-0.4 \mathrm{~V}$ and -0.4 to $-0.6 \mathrm{~V}$. Further, in the case of Fe-NT-600 
electrode, the redox peaks were shifted toward less negative potentials compared to those of $\mathrm{Fe}$ NT-400 and Fe-NT-500 electrodes (Inset Fig. 6a). Similar shift in peak potentials were also reported in the case of $\mathrm{Fe}^{3+} / \mathrm{Fe}^{2+}$-Bromine redox flow cell, probably due to high solubility of the electrode in the electrolyte [46]. On the other hand, the redox peaks were not so well defined in the case of Fe-NT-200 and Fe-NT-700 electrodes.

The area specific capacitance (C) of the electrodes (at $100 \mathrm{mV} \mathrm{s}^{-1}$ ) were calculated following the integrated area of the CV curves (Fig. 6a) according to the following equation,

$C=Q / 2(\Delta V A)$

where, $Q, \Delta V$ and $A$ are the charge from the $\mathrm{CV}$ curve, potential window, and the active area of the electrode in contact with the electrolyte, respectively. The variations in the specific capacitance of the Fe-NT electrodes are presented in Figure 6(b). The figure clearly demonstrates the superior supercapacitance behavior of the Fe-NT-300 compared to the other electrodes. For instance, the specific capacitance of the Fe-NT electrode was increased by approximately 8 fold upon increase in the annealing temperature from 200 to $300^{\circ} \mathrm{C}$. When the annealing temperature was raised above $300^{\circ} \mathrm{C}$, the capacitance of the electrodes started diminishing. Capacitance values for the Fe-NT-400 and Fe-NT-500 electrodes were close to 45 and 18\%, respectively, of the value obtained for the Fe-NT-300 electrode

The effect of scan rates on the capacitive performance of the Fe-NT electrodes were carried out by CV cycling at multiple scan rates. The representative profiles for the Fe-NT-300 and Fe-NT-400 electrodes are shown in Figure 7. The CV profiles were recorded at the scan rates of 20, 100 and $200 \mathrm{mV} \mathrm{s}^{-1}$ for both electrodes. In both cases, the shape of the CV curves did not change significantly with increase in the scan rate suggesting good stability of the electrodes 
at high charge-discharge (high CV currents) conditions. Increase in the current values was observed with increase in scan rates for both electrodes. However, it is worth noting here that Feoxide electrode generally shows some amount of equivalent series resistance (ESR) [2, 17, 18, 44]. The detailed mechanisms of the surface absorption/desorption of electrolytic ions (in this case sulfate ions) and the redox behavior of the Fe-oxide are not clearly understood and needs further studies (For example in situ spectroscopic study) to establish clearly, as also pointed out in some previous studies $[12,44]$.

The specific capacitance of the Fe-NT electrodes at various scan rates was determined using Eqn. 1 and presented in Figure 7(c). For all electrodes, a decreasing trend of specific capacitance was observed with increasing scan rate. This is because of the fact that at lower current densities, more effective insertion of the ionic species (e.g., $\mathrm{Li}^{+}$ions) of the electrolyte occurs on the electrode surface that leads to enhanced capacitance. However, at higher scan rates, these ions have less time for insertion on the surface of the electrode. Therefore, a decrease in capacitance is observed with increase in the scan rate. In Figure 7(c), the maximum specific capacitance was observed for Fe-NT-300 electrode at a scan rate of $20 \mathrm{mV} \mathrm{s}^{-1}\left(187 \mathrm{mF} \mathrm{cm}^{-2}\right)$. Upon increase in the scan rate to $200 \mathrm{mV} \mathrm{s}^{-1}$, the capacitance of the electrode decreased by approximately $27 \%$. Similarly, the decrease in specific capacitance for the Fe-NT-400 and FeNT-500 electrodes were about $39 \%$ and $25 \%$, respectively upon increase in the scan rate from 20 to $200 \mathrm{mV} \mathrm{s}^{-1}$. On the other hand, the specific capacitance for all other electrodes were found to be relatively low $\left(<40 \mathrm{mF} \mathrm{cm}^{-2}\right)$ together with a near $20 \%$ decrease in capacitance upon increase in the scan rate from 20 to $200 \mathrm{mV} \mathrm{s}^{-1}$.

The stability of the Fe-NT electrodes were evaluated by conducting repeated CV cycling at a scan rate of $200 \mathrm{mV} \mathrm{s}^{-1}$ for up to 200 cycles for the Fe-NT-300 and Fe-NT-400 electrodes. 
The superimposed CV profiles obtained after the $1^{\text {st }}$ and $200^{\text {th }}$ cycle are shown in Figure 8 for these electrodes. It can be observed that a significant portion of capacitance was retained in both electrodes even after undergoing a large number of CV cycles demonstrating excellent cycle stability and high retention of capacitance. Further, the shape of the profiles was also merely unchanged after the repetitive $\mathrm{CV}$ cycles indicating stable and reversible electrochemical reactions.

The discharge behavior of some of the Fe-NT electrodes were examined by galvanostatic discharge test in the potential range from 0 to $-0.8 \mathrm{~V}$ at a current density of $1 \mathrm{~mA} \mathrm{~cm}{ }^{-2}$. The following electrodes, Fe-NT-300, Fe-NT-400, and Fe-NT-500 were used for this analysis and the recorded voltage-time (V-t) profiles are presented in Figure 9(a). The specific capacitance of the electrodes was obtained using the relationship,

$C=I t / \Delta V A$

where, $I$ represents the discharge current density, $t$ is the discharge time, $\Delta V$ is the voltage window, $A$ is the area of the electrode. The specific capacitance, calculated from the discharging curves using Eqn. 2, were found to be about 362, 204 and $111 \mathrm{mF} \mathrm{cm}^{-2}$ for the Fe-NT-300, FeNT-400, and Fe-NT-500 electrodes, respectively. As demonstrated in the CV results, the galvanostatic discharge experiments also suggested the enhanced specific capacitance for the FeNT-300 electrode in comparison to the other Fe-NT electrodes.

Based on the results obtained from the galvanostatic discharge experiments, galvanostatic charge-discharge experiments were conducted on the Fe-NT-300 electrode at various current densities. Figure 9(b) shows the voltage-time (V-t) profiles for the electrode obtained at current densities of 1,4 , and $6 \mathrm{~mA} \mathrm{~cm}{ }^{-2}$ in the potential window of 0 to $-0.8 \mathrm{~V}$. The charge and discharge 
profiles showed variations in slope indicating that the potential is dependent on the time, which suggests pseudocapacitance nature of the electrode. The slope variations result from the electrochemical adsorption-desorption of redox species at the electrode/electrolyte interface. The redox behavior was also observed in the $\mathrm{CV}$ profile obtained for this electrode (Fig. 6a). Based on Eqn. 2, the specific capacitance of the Fe-NT-300 electrode were calculated to be approximately 362,314 , and $257 \mathrm{mF} \mathrm{cm}^{-2}$ at the current densities 1,4 , and $6 \mathrm{~mA} \mathrm{~cm} \mathrm{~cm}^{-2}$, respectively. It to be noted the Fe-oxide based supercapacitor electrode show relatively high internal resistance between the electrode/electrolyte systems [17, 18, 44]. This is more so prominent in the case of sulfate ion containing electrolyte and the resistance may be due to some complicated mechanism of sulfate ion absorption/desorption characteristics as pointed out by Lee and coworker [44]. This is characterized by a sudden voltage drop (IR drop) as indicated in Fig. 9a (also in Fig. 9b), and this behavior is quite consistent with previous findings $[18,44]$.

The stability of the Fe-NT electrodes was evaluated by conducting continuous chargedischarge experiments (more than 1000 cycles) at a constant current density of $4 \mathrm{~mA} \mathrm{~cm}^{-2}$. For this purpose, Fe-NT-300 and Fe-NT-400 electrodes were used. Figure 10(a) shows the representative $\mathrm{V}$-t curves obtained in these two electrodes during the beginning of the continuous charge-discharge cycle. Figure 10(b) shows the variation of the specific capacitance of the electrodes as the function of the cycle number (till 500 cycles). The figure shows that both electrodes demonstrated excellent stability of the capacitance behavior even after 500 cycles of charge-discharge. The specific capacitance for the Fe-NT-300 electrode was $\sim 314 \mathrm{mF} \mathrm{cm}^{-2}$ at the beginning of cycling and decreased to about $249 \mathrm{mF} \mathrm{cm}^{-2}$ after 500 cycles. The retention in capacitance was over $80 \%$. High capacitance retention ( $~ 80 \%)$ was also observed for the Fe-NT400 electrode. Further, the electrodes showed no degradation even after the $1000^{\text {th }}$ charge- 
discharge cycles (Fig. 10c\&d) indicating their excellent cycle stabilities. The high specific capacitance and excellent stabilities of the electrodes demonstrates nanotubular iron oxide electrode as a possible candidate material for supercapacitor application.

The influence of annealing temperature of the electrode material on its capacitive performance has been studied in the past [47-49]. For example, Fang et al. [47] annealed $\mathrm{RuO}_{2}$ electrode prepared electrochemically at various temperatures of 100,200 and $400^{\circ} \mathrm{C}$. They reported that a threshold crystallization temperature $\left(200^{\circ} \mathrm{C}\right)$ was required to create suitable nanostructured oxide that promoted formation of interpenetrating percolation paths for efficient electronic/protonic conductions for enhanced supercapacitance. In another study [48], $\mathrm{V}_{2} \mathrm{O}_{5}$ electrodes were annealed at various temperatures, in the range of $250-400^{\circ} \mathrm{C}$, and the best capacitance values were observed after annealing at $300^{\circ} \mathrm{C}$. The authors reported that an optimum annealing temperature is required so as to achieve best structural order/symmetry in the electrode material. The authors also suggested that annealing at $300^{\circ} \mathrm{C}$ resulted in decreased bulk resistance (explained using EIS analysis) and thereby increasing the ionic conductivity and the specific capacitance of the electrode material. Subsequently, we have conducted EIS analysis to better understand the conductivity properties of the Fe-NT electrodes.

Figure 11 shows the Nyquist plot of Fe-NT-300 and Fe-NT-400. In this plot, the frequency increases from right to left. For both electrodes, at low frequencies the imaginary part of the resistance sharply increases tending toward a vertical line, which is characteristic of ideal capacitive behavior. Deviation from ideal capacitive behavior at lower frequencies is due to the porosity of the electrode. At higher frequencies the resistance as well as the capacitance of the electrodes decreases as a result of only part of the active porous layer accessible at higher frequencies [50]. From these plots, useful information such as bulk and interfacial resistance can 
be estimated. Two depressed semicircle arcs are observed in both Fe-NT-300 and Fe-NT-400 with one at high and one at low frequency. The depressed semicircular arcs are indicative of a distribution of relaxation times [51]. Moreover, the two observed semicircular arcs are associated with bulk (high frequency) and interfacial (low frequency) processes. The intersection of the high frequency arc with the real impedance axis (x-axis) corresponds to the combined resistance of the electrolyte resistance, electrode resistance, and the electrode/electrolyte interfacial resistance [52]. The combined overall resistance was determined to be $\sim 5 \Omega \mathrm{cm}^{2}$ and $\sim 6.5 \Omega \mathrm{cm}^{2}$ for Fe-NT-300 and Fe-NT-400, respectively. Furthermore, the magnitude of the second arc can qualitatively be used as an indication of relative charge transfer resistance, where a smaller arc is representative of low charge transfer resistance (polarization resistance). The lower interfacial and overall resistance, along with higher capacitance at lower frequency account for the higher specific capacitance of the Fe-NT-300 electrode compared to the Fe-NT-400 electrode.

\section{Conclusion}

The influence of annealing temperature on the supercapacitance behavior of nanotubular iron oxide electrode has been evaluated. The evolution of crystal phases of the Fe-NT electrodes, after annealing in air at various temperatures $\left(200-700^{\circ} \mathrm{C}\right)$, were studied with the help of XRD and XPS techniques. The XRD studies indicated that the annealing of the Fe-NTs created predominantly $\alpha-\mathrm{Fe}_{3} \mathrm{O}_{4}$ phase irrespective of the temperature employed. The results were also supported by the XPS studies. The supercapacitance properties of the Fe-NT electrodes were evaluated using cyclic voltammetry as well as galvanostatic charge-discharge experiments. It was observed that the annealing at $300^{\circ} \mathrm{C}$ imparted the highest specific capacitance (> $300 \mathrm{mF}$

$\mathrm{cm}^{-2}$ ) in the electrode among all other annealing temperature. The supercapacitance properties of the electrodes annealed at 400 and $500^{\circ} \mathrm{C}$ were also sufficiently higher (between $100-200 \mathrm{mF} \mathrm{cm}^{-}$ 
${ }^{2}$ ) compared to the electrodes annealed at 200,600 and $700^{\circ} \mathrm{C}$. The highest capacitance obtained for the electrode annealed at $300^{\circ} \mathrm{C}$ was also in accordance to the low bulk resistance (higher ionic conductivity) observed in this electrode from EIS studies. High capacitance retention (> $80 \%$ ) was achieved in the electrodes annealed at 300 and $400^{\circ} \mathrm{C}$ even after 1000 cycles of continuous charge-discharge operation. In summary, high specific capacitance and excellent capacitance retention even after long charge-discharge cycle qualify Fe-NTs as a cheap and economical supercapacitor material.

\section{Acknowledgement}

The U.S. Department of Energy (DE-FC-36-06GO86066) supported the work presented here. 


\section{References}

1. T. Brezesinski, J. Wang, S. H. Tolbert, B. Dunn, Nat. Mater., 9, (2010), 146-151

2. B. E. Conway, Electrochemical Supercapacitors, (1999), Kluwer Academic, New York

3. B. Sarma, Y.R. Smith, A. L. Jurovitzki, R.S. Ray, S.K. Mohanty, M. Misra, J. Power Sources, 236, (2013), 103

4. K. Xie, J. Lie, Y. Lai, W. Lu, Z. Zhang, Y. Liu, L. Zhou, H. Huang, Electrochem. Commun. 13 (2011) 657.

5. D. Pech, M. Brunet, H. Durou, P. Huang, V. Mochalin, Y. Gogotsi, P.-L. Taberna, P. Simon, Nat. Nanotechnol., 5, (2010), 651-654

6. Y. Xie, D. Fu, Materials Chemistry and Physics, 122 (2010), 23-29

7. X. Wang, B. D. Myers, J. Yan, G. Shekhawat, V. Dravid, P. S. Lee, Nanoscale, 5, (2013), $4117-4122$

8. A. K. Singh, D. Sarkar, G. G. Khan, K. Mandal, J. Mater. Chem. A, 1, (2013), 12759-12767

9. B. Sarma, R. S. Ray, S.K. Mohanty, M. Misra, Applied Surface Science, 2014, 300, 29-36

10. B. Sarma, Y.R. Smith, A. L. Jurovitzki, S.K. Mohanty, M. Misra, ACS Appl Mater Interfaces, 5, (2013), 1688-1697

11. S.Y. Wang, K.C. Ho, S.L. Kuo, N.L. Wu, J. Electrochem. Soc., 153, (2006), A75

12. T. Cottineau, M. Toupin, T. Delahaye, T. Brousse, D. Belanger, Appl. Phys. A: Mater. Sci. Process. 82, (2006), 599-606

13. M. Nasibi, M. A. Golozar, G. Rashed, Materials Letters, 85, (2012), 40-43

14. X. Du, C. Wang, M. Chen, Y. Jiao, J. Wang, J. Phys. Chem. C, 113, (2009), 2643-2646

15. N.L. Wu, S.Y. Wang, C.Y. Han, D.S. Wu, L.R. Shiue, J. Power Sources, 113, (2003), 173178

16. P.M. Kulal, D.P. Dulal, C.D. Lokhande, V.L. Fulari, J. Alloy Compd., 509, (2011), 25672571

17. J. Chen, K. Huang, S. Liu, Electrochimica Acta, 55, (2009), 1-5

18. S. Shivakumara, T. R. Penki, N. Munichandraiah, J. Electrochem. Soc., 2, (2013), A60-A62

19. G. Binitha, M. S. Soumya, A. A. Madhavan, P. Praveen, A. Balakrishnan, K. R. V. Subramanian, M. V. Reddy, S. V. Nair, A. S. Nair, N. Sivakumar, J. Mater. Chem. A, 1, (2013), 11698

20. M.-S. Wu, R.-H. Lee, J. Electrochem. Soc., 156, (2009), A737-743

21. M. Misra, K.S. Raja, in: L. Vayssieres (Ed.), On Solar Hydrogen \& Nanotechnology, John Wiley \& Sons, Chichester, UK., 2010

22. H. Masuda, K. Fukuda, Science, 268, (1995), 1466

23. V. Zwilling, M. Aucouturier, E. Darque-Ceretti, Electrochem. Acta, 45, (1999), 921

24. B. Sarma, Y.R. Smith, S.K. Mohanty, M. Misra, Mater. Lett., 85, (2012), 33-36

25. Y.R. Smith, B. Sarma, S.K. Mohanty, M. Misra, Electrochem. Commun., 19, (2012), 131134

26. P. Roy, S. Berger, P. Schmuki, Angew. Chem., 50, (2011), 2904-2939

27. Y. Smith, B. Sarma, S. Mohanty, M. Misra, Int. Journal of Hydrogen Energy, 38 (2013) 2062-2069

28. Y. Smith, B. Sarma, S. Mohanty, M. Misra, Applied Materials \& Interfaces, 4 (2012) 58835890 
29. Y. Smith, R.S. Ray, K. Carlson, B. Sarma, M. Misra, Materials, 6 (2013) 2892-2957

30. R. S. Ray, B. Sarma, S. Mohanty, M. Misra, Talanta, 118(2014) 304-311

31. R.R. Rangaraju, K.S. Raja, A. Panday, M. Misra, Electrochem. Acta, 55, (2010), 785-793

32. S. K. Mahapatra, S.E John, S. Banerjee, M. Misra, Chem. Mater., 21, (2009), 3048-3055

33. S. P. Albu, A. Ghicov, P. Schmuki, Phys. Status Solidi RRL, 3, (2009), 64-66

34. G. R. Patzke, F. Krumeich, R. Nesper, Angew. Chem. Int. Ed., 41, (2002), 5000 - 5015

35. L. Zhang, H. Lin, N. Wang, C. Lin, J. Li, Journal of Alloy and Compounds, 431, (2007), 230235

36. M. Zhang, Z. Jin, J. Zhang, X. Guo, J. Yang, W. Li, X. Wang, Z. Zhang, J. Mol. Catal. A, 217, (2004), 203-210

37. S. Zhang, W. Li, Z. Jin, J. Yang, J. Zhang, Z. Du, Z. Zhang, J. Solid State Chem., 177, (2004), 1365-1371.

38. Y.Cudennec, A. Lecerf, J. Solid State Chem. 179 (2006) 716-722

39. D. K. Bora, A. Braun, S. Erat, O. Safonova, T. Graule, E. C. Constable, Current Applied Physics, 12, (2012), 817-825

40. P.C.J. Graat, M.A.J. Somers, Appl. Surf. Sci. 100, (1996), 36.

41. P. Mills, J.L. Sullivan, J. Phys. D: Appl. Phys. 16, (1983), 723

42. D.D. Hawn, B.M. DeKoven, Surf. Interface Anal. 10, (1987), 63

43. M. Muhler, R. Schlogl, G. Ertl, J. Catal. 138 (1992) 413

44. K. K. Lee, S. Deng, H. M. Fan, S. Mhaisalkar, H. R. Tan, E. S. Tok, K. P. Loh, W. S. Chin, C. H. Sow, Nanoscale, 4, (2012) 2958

45. C. Wu, P. Yin, X. Zhu, C. O. Yang, Y. Xie, J. Phys. Chem. B 110, (2006), 17806-17812

46. Y. H. Wen, H. M. Zhang, P. Qian, H. T. Zhou, P. Zhao, B. L. Yi, Y. S. Yang, Journal of The Electrochemical Society, 153, 2006, A929-A934

47. W.-C. Fang, J.-H. Huang, L.-C. Chen, Y.-L. O. Su, K.-H. Chen, J. Power Sources, 160, (2006), 1506-1510

48. K. Jeyalakshmi, S. Vijayakumar, S. Nagamuthu, G. Muralidharan, Materials Research Bulletin, 48, (2013), 760-766

49. S. Yang, Y. Sun, L. Chen, Y. Hernandez, X. Feng, K. Mullen, Scientific Reports, 2, (2012), 427; doi: $10.1038 /$ srep00427

50. R. Kotz; M. Carlen, Electrochim. Acta, 45, 2000, 2483-2498

51. K. S. Cole; R. H. Cole, J. Chem. Phys., 9, 1941, 341

52. Y-g. Wang; Y-y. Xia, Electrochim. Acta, 51, 2006, 3223-3227. 
Figure 1: Self-organized and vertically aligned iron oxide nanotube (Fe-NT) structures formed after anodization at 50V for 30 minutes (without anneal), the inset shows the cross sectional view of the tubular arrays.

Figure 2: Morphology of the Fe-NT after annealing for $2 \mathrm{hrs}$ at (a) $200^{\circ} \mathrm{C}$, (b) $300^{\circ} \mathrm{C}$, (c) $400^{\circ} \mathrm{C}$, (d) $500^{\circ} \mathrm{C}$, (e) $600^{\circ} \mathrm{C}$, The figure (f) shows the cross-sectional view of the transformed nanorods at $600^{\circ} \mathrm{C}$

Figure 3: Demonstration of various morphologies of the Fe-NT evolved after annealing at $700^{\circ} \mathrm{C}$

Figure 4: The XRD profiles of Fe-NT electrodes after annealing for $2 \mathrm{hrs}$ at various temperatures

Figure 5: (a) XPS survey spectra for Fe-NT electrodes after annealing at 300 and $400^{\circ} \mathrm{C}$. XPS spectra for (b) Fe 2p, and (c) O1s from these electrodes

Figure 6: (a) $\mathrm{CV}$ profiles of the Fe-NT electrodes annealed at various temperatures recorded at $100 \mathrm{mV} \mathrm{s}^{-1}$. Inset figure shows the enlarged profiles for electrodes annealed at 200, 500, 600 and $700^{\circ} \mathrm{C}$ along with the as-anodized Fe-NT electrode. (b) Variations in specific capacitance plotted vs the annealing temperature

Figure 7: $\mathrm{CV}$ profiles of the Fe-NT electrodes annealed at (a) $300^{\circ} \mathrm{C}$ and (b) $400^{\circ} \mathrm{C}$ recorded at various scan rates. (c) Variation of specific capacitance of the Fe-NT electrodes as the function of scan rates

Figure 8: The $1^{\text {st }}$ and $200^{\text {th }} \mathrm{CV}$ profiles recorded at a scan rate of $200 \mathrm{mV} \mathrm{s}^{-1}$ for the Fe-NT electrodes annealed (a) $300^{\circ} \mathrm{C}$ and (b) $400^{\circ} \mathrm{C}$. Very stable capacitance can be observed in both annealing conditions 
Figure 9: (a) Galvanostatic discharge (V-t) profiles obtained at a current density of $1 \mathrm{~mA} \mathrm{~cm}^{-2}$ for the Fe-NT electrodes annealed at 300,400 and $500^{\circ} \mathrm{C}$. (b) Galvanostatic charge-discharge (V-t) profiles obtained for the Fe-NT electrodes annealed at $300^{\circ} \mathrm{C}$ recorded at various current densities of 1,4 , and $6 \mathrm{~mA} \mathrm{~cm}^{-2}$.

Figure 10: (a) Representative V-t profiles recorded at the current density of $4 \mathrm{~mA} \mathrm{~cm}^{-2}$ for Fe-NT electrodes annealed at 300 and $400^{\circ} \mathrm{C}$. The experiments were conducted for up to a total of 1000 cycles. (b) The variations in the specific capacitance with cycle number for the electrodes for 500 cycles. The V-t curves obtained for the electrode after annealing at (c) $300^{\circ} \mathrm{C}$ and (d) $400^{\circ} \mathrm{C}$ after $1000^{\text {th }}$ charge-discharge cycle.

Figure 11: Nyquist plot of Fe-NT electrodes annealed at 300 and $400^{\circ} \mathrm{C}$ carried out at $-0.5 \mathrm{~V}$ (vs $\mathrm{Ag} / \mathrm{AgCl}$ ) in the frequency range of $100-0.05 \mathrm{~Hz}$ with an imposed $\mathrm{AC}$ potential of $10 \mathrm{mV}$ in 1.0 $\mathrm{M} \mathrm{Li}_{2} \mathrm{SO}_{4}$ electrolyte 

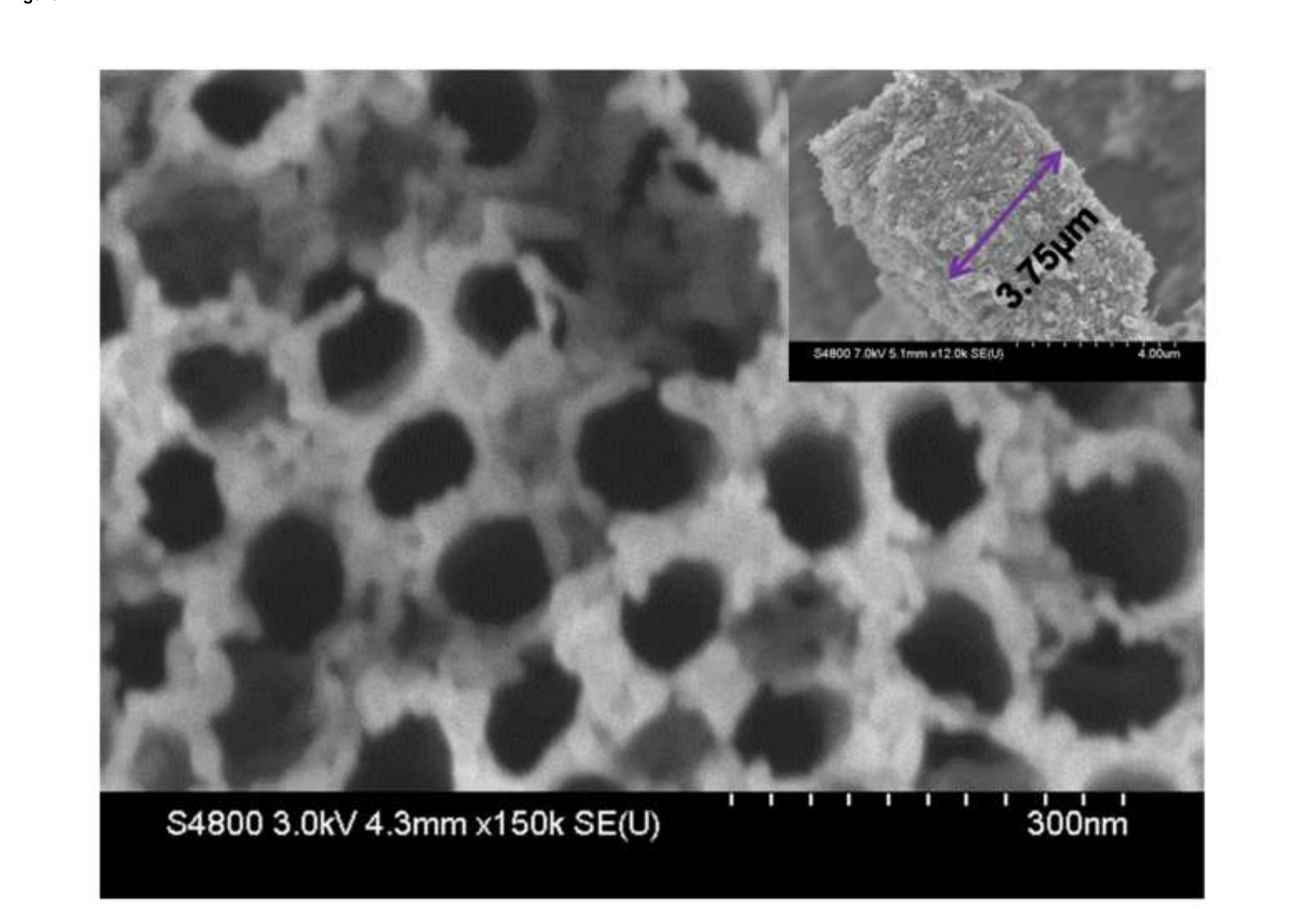

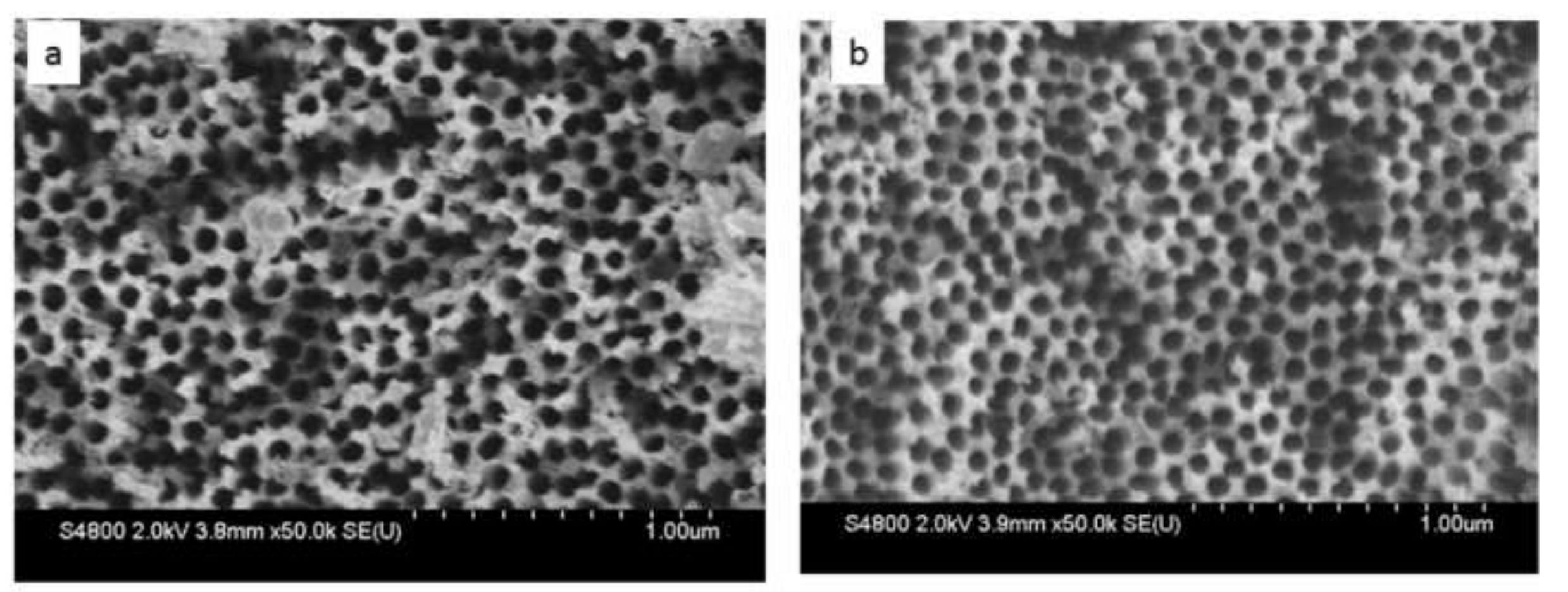

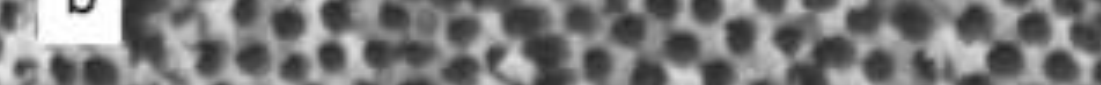

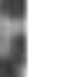
. .

.




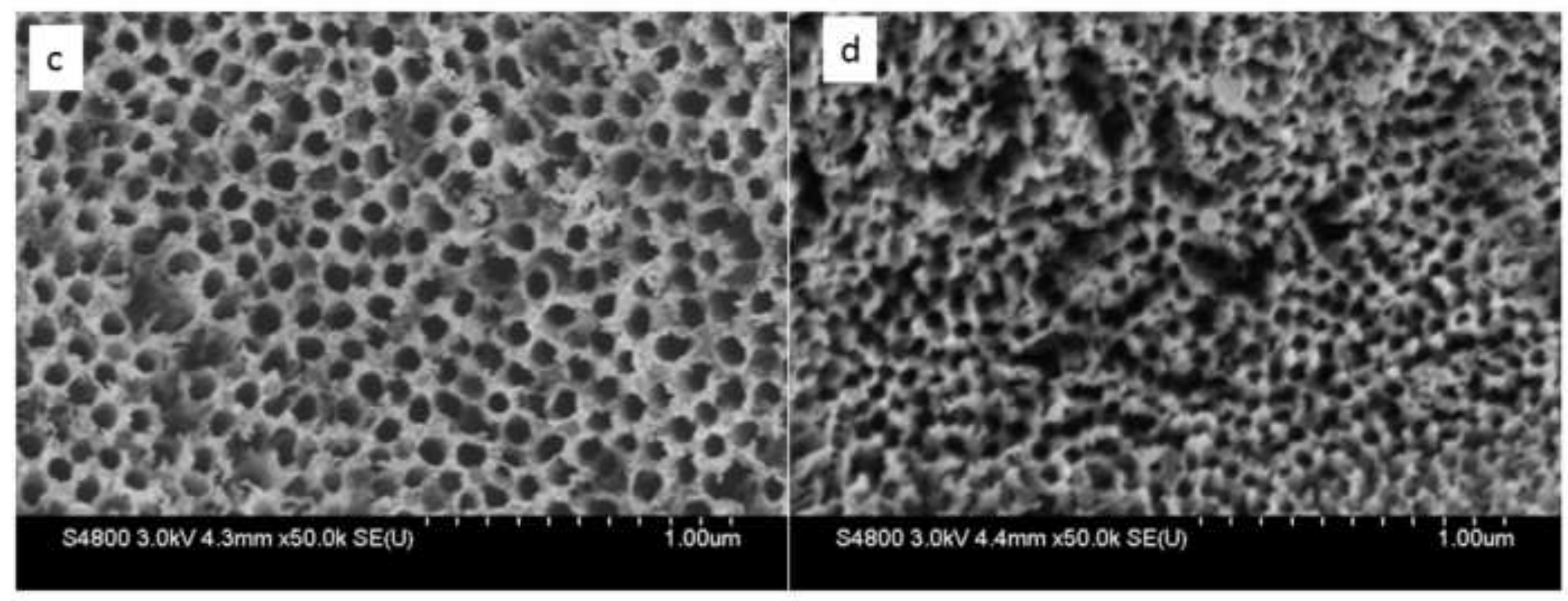

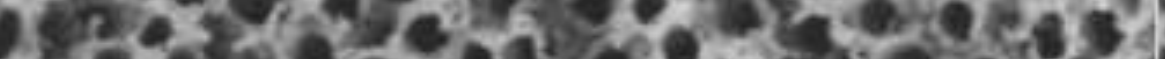

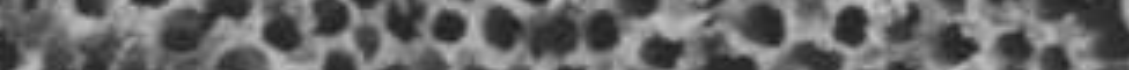

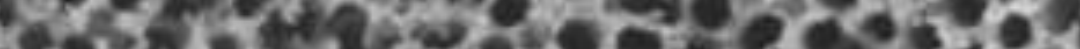

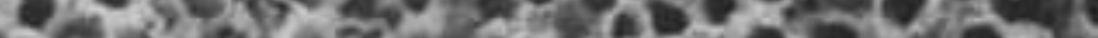



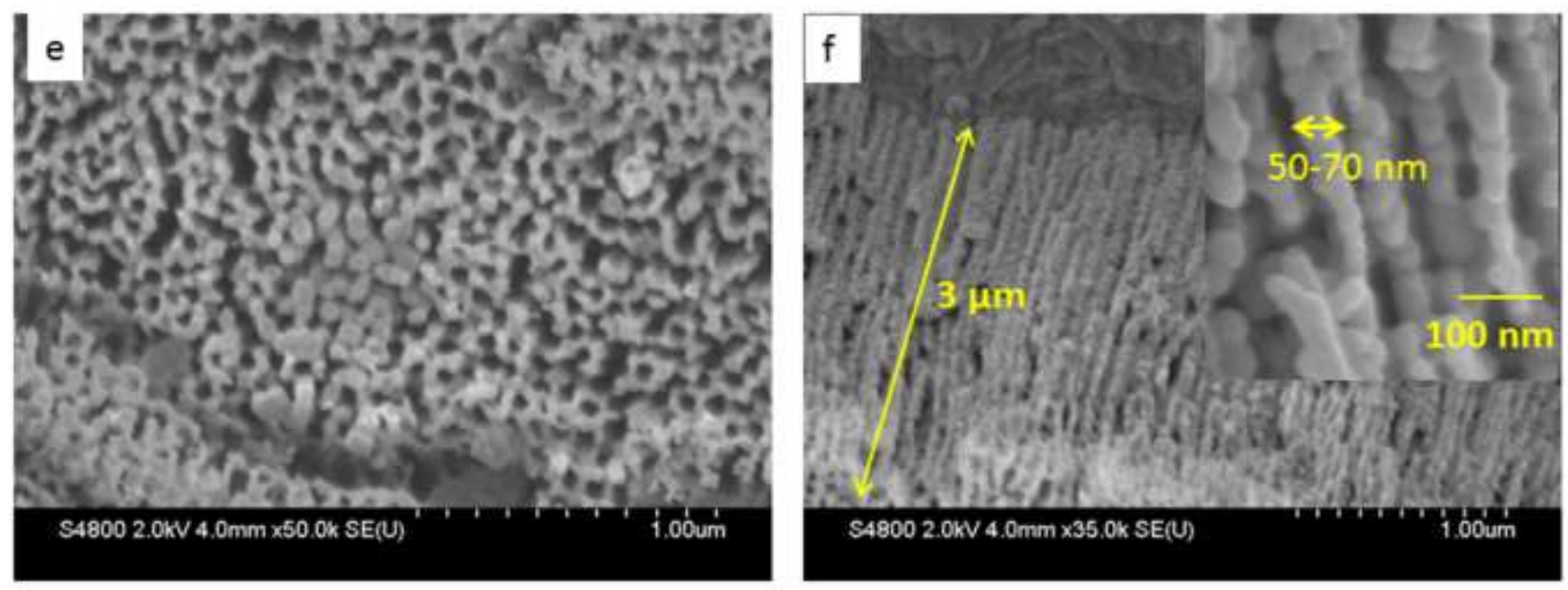

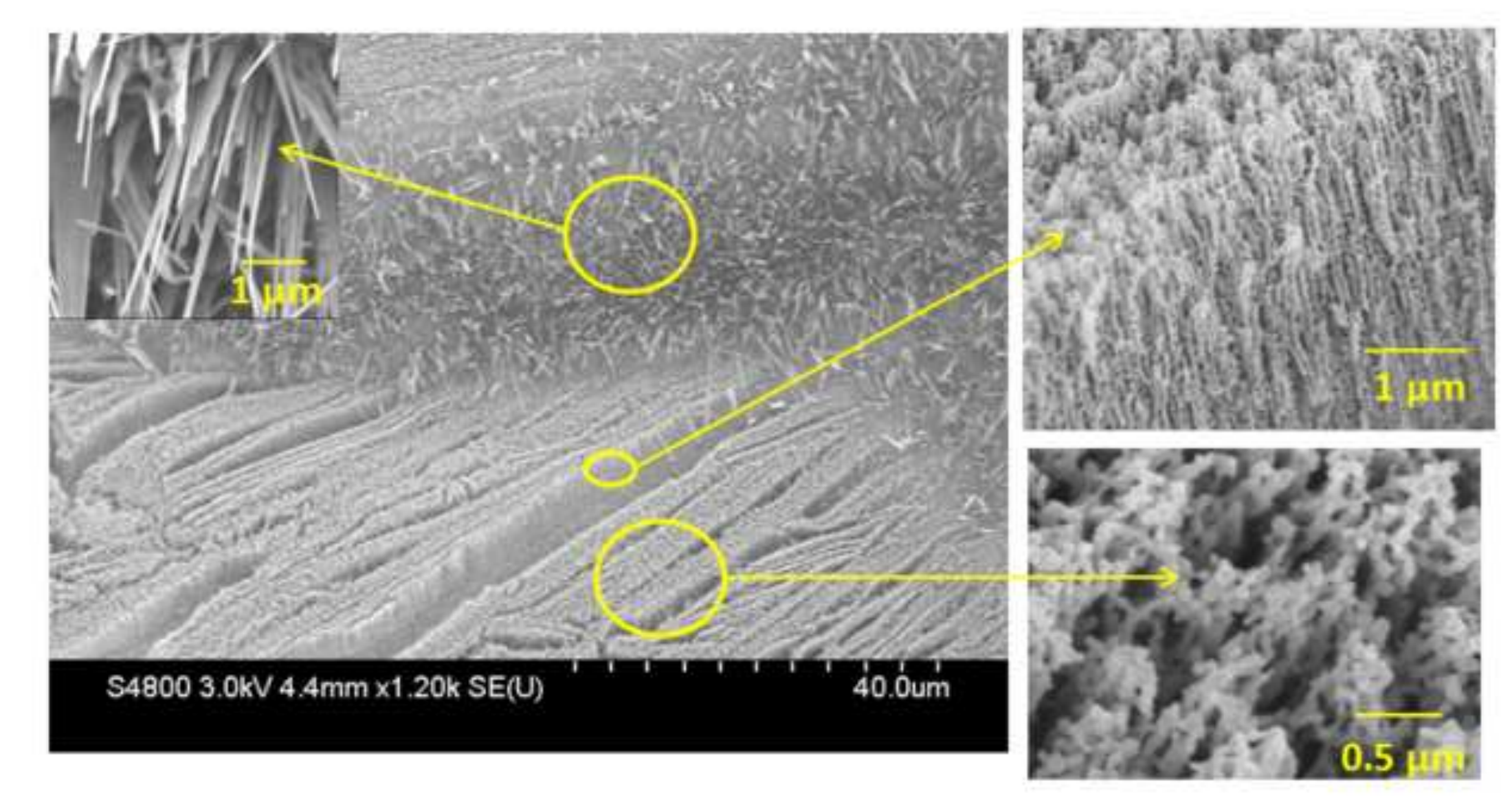

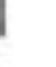

. 


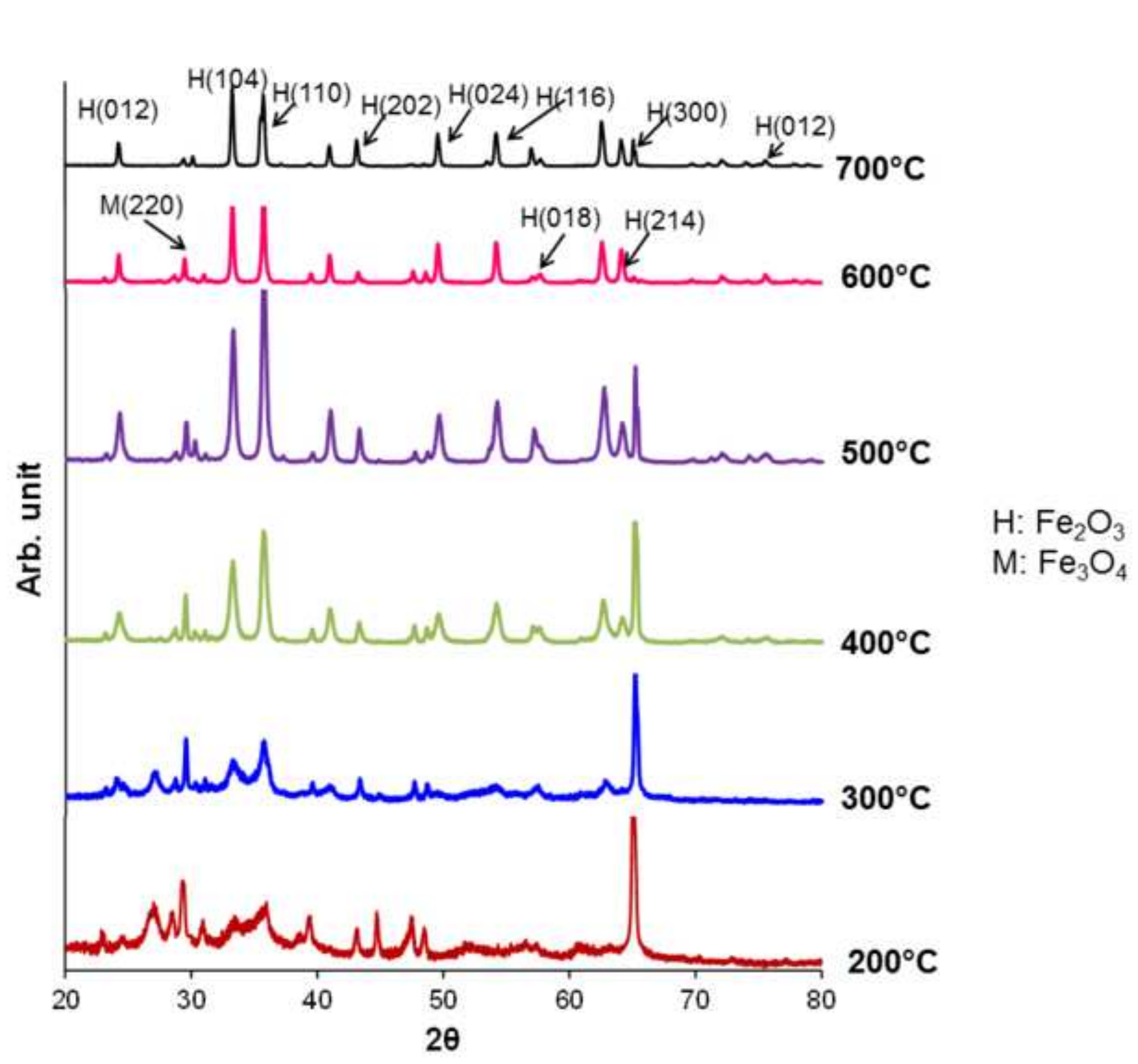




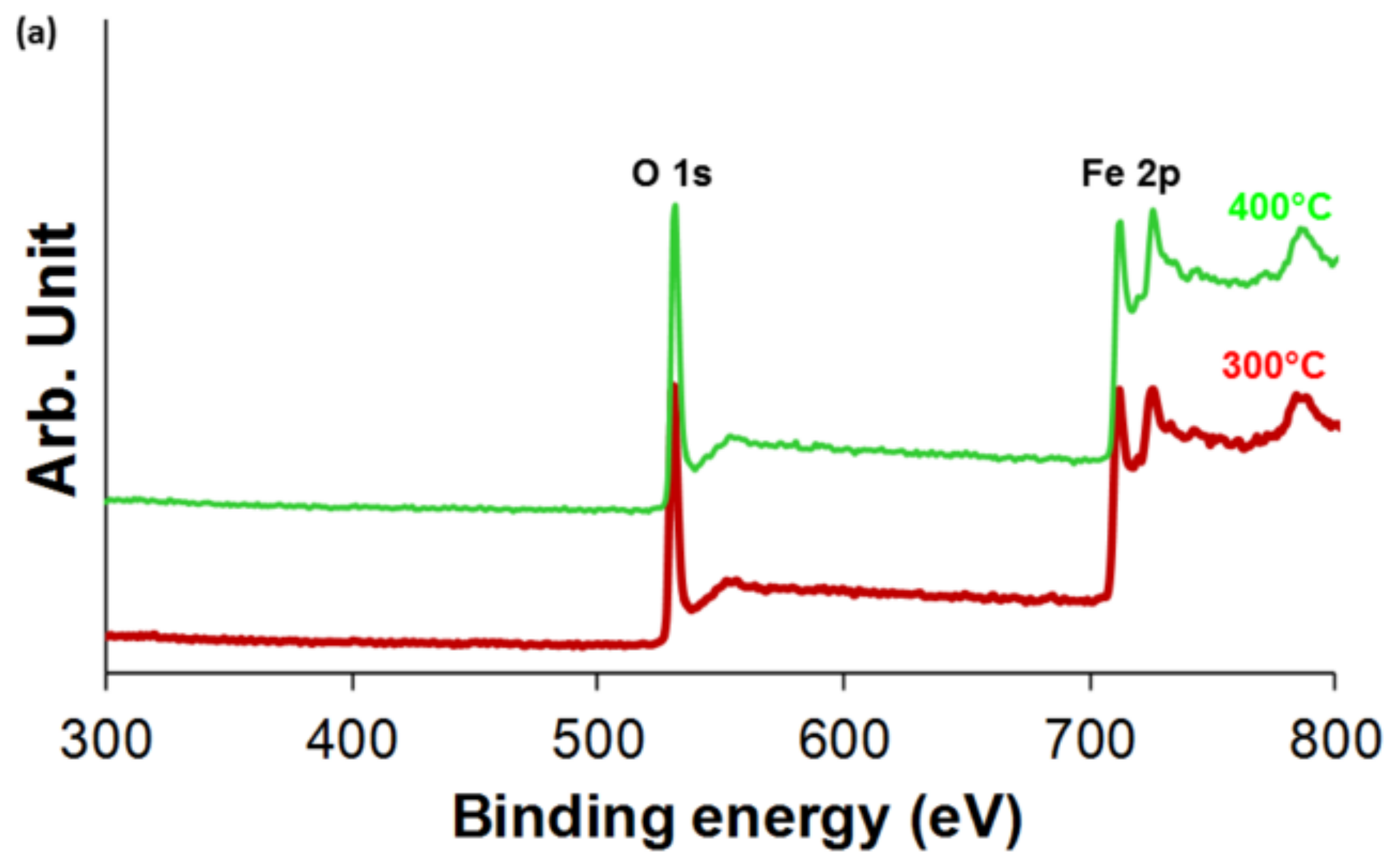




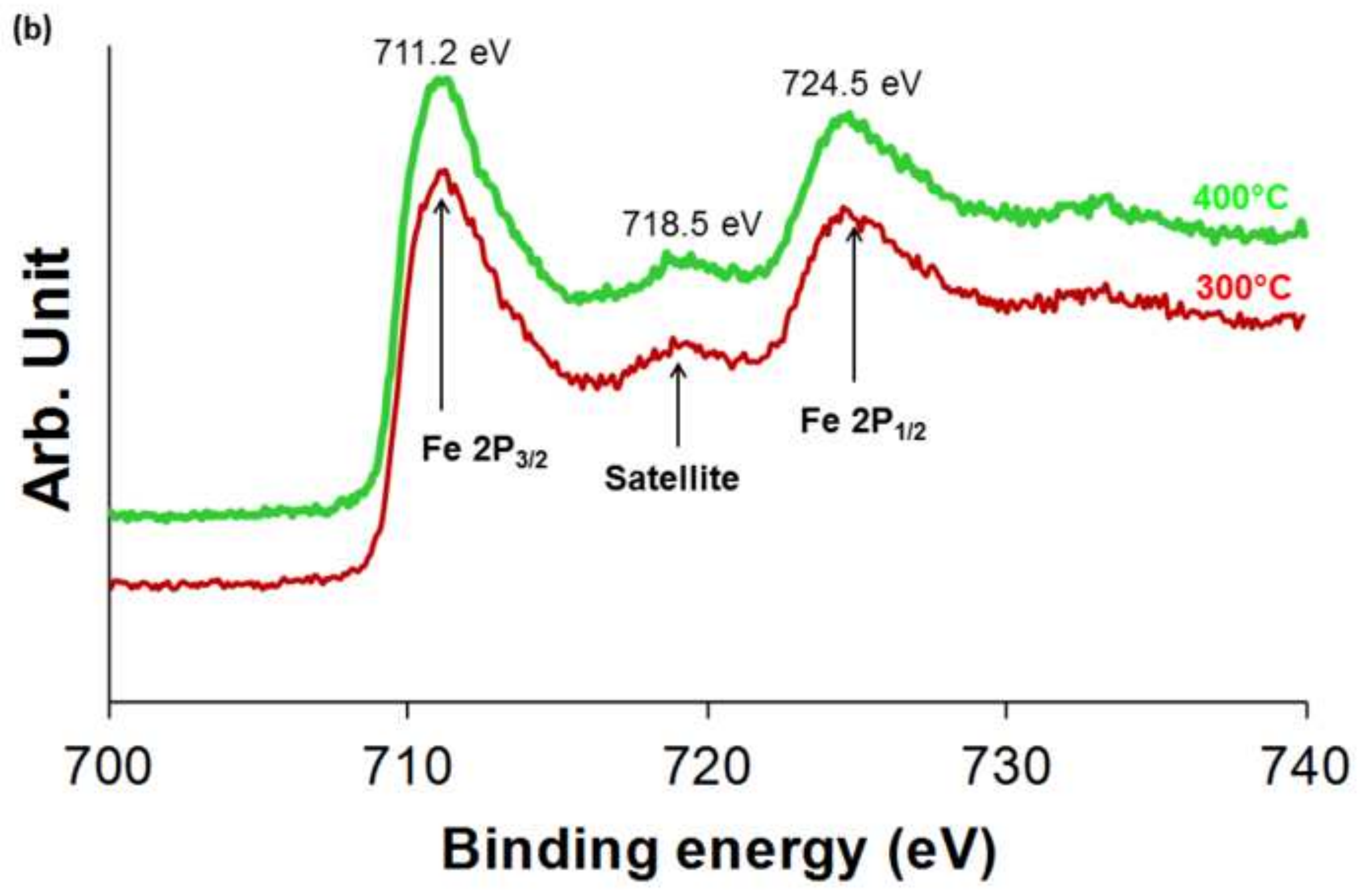




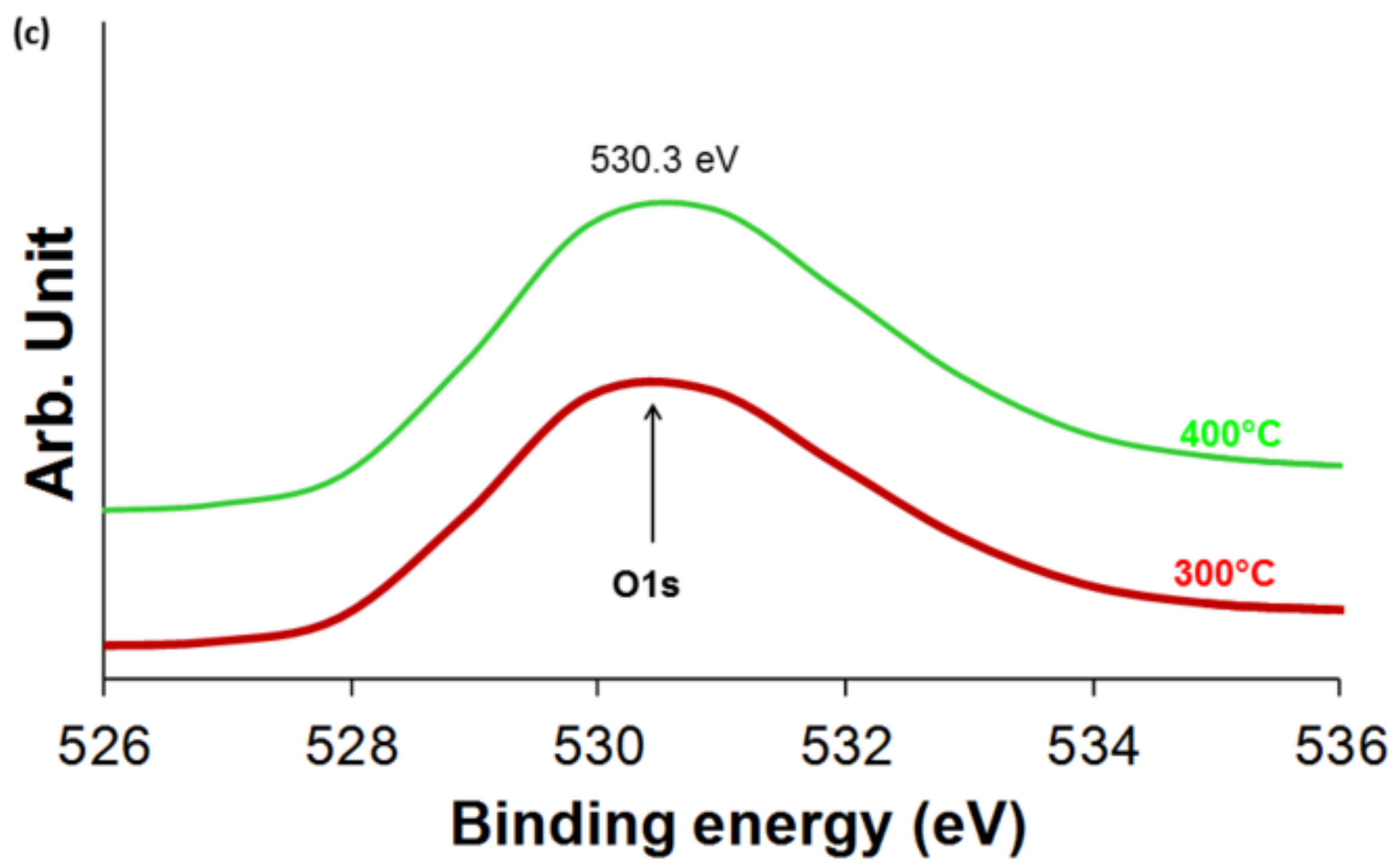




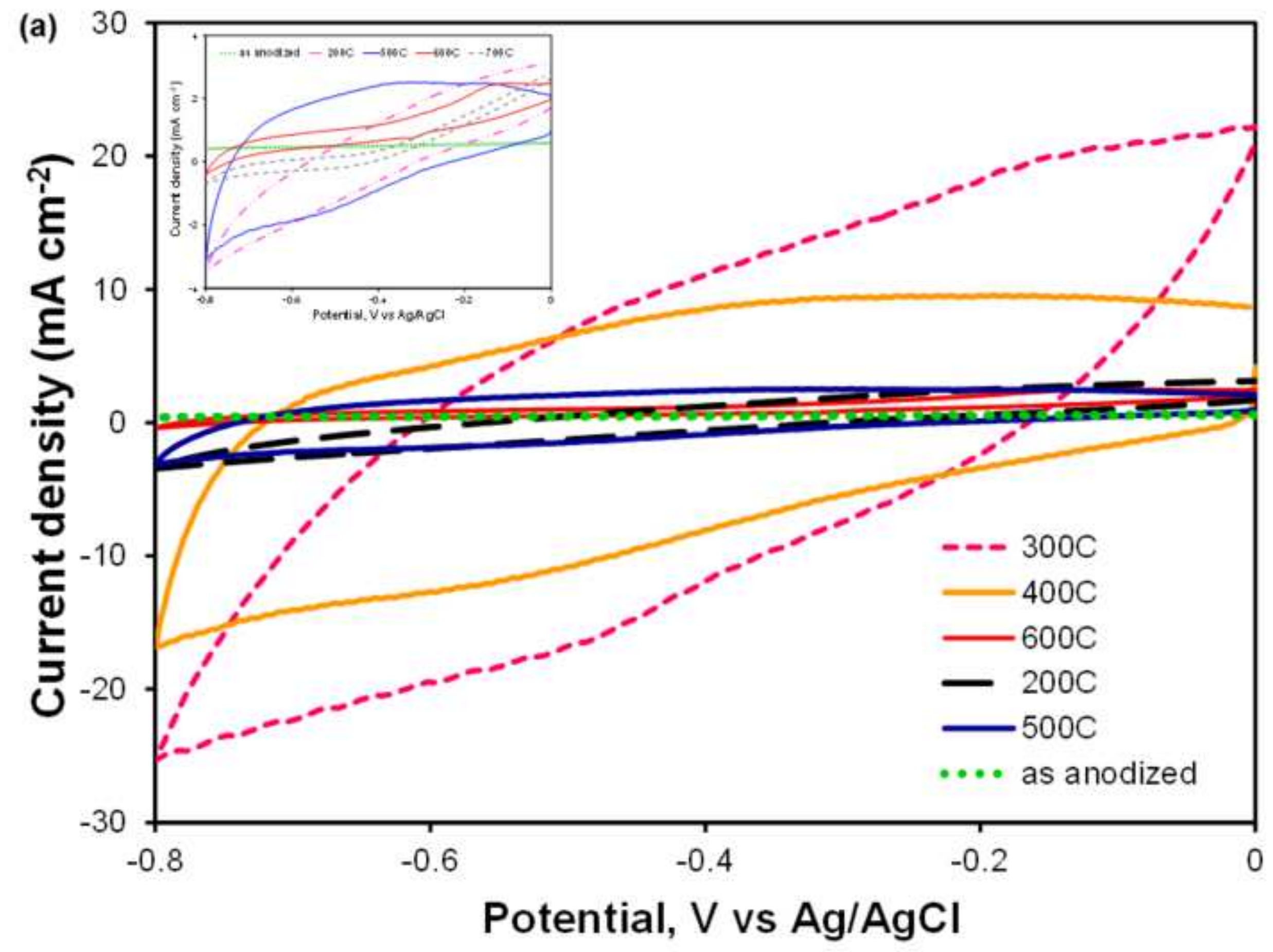




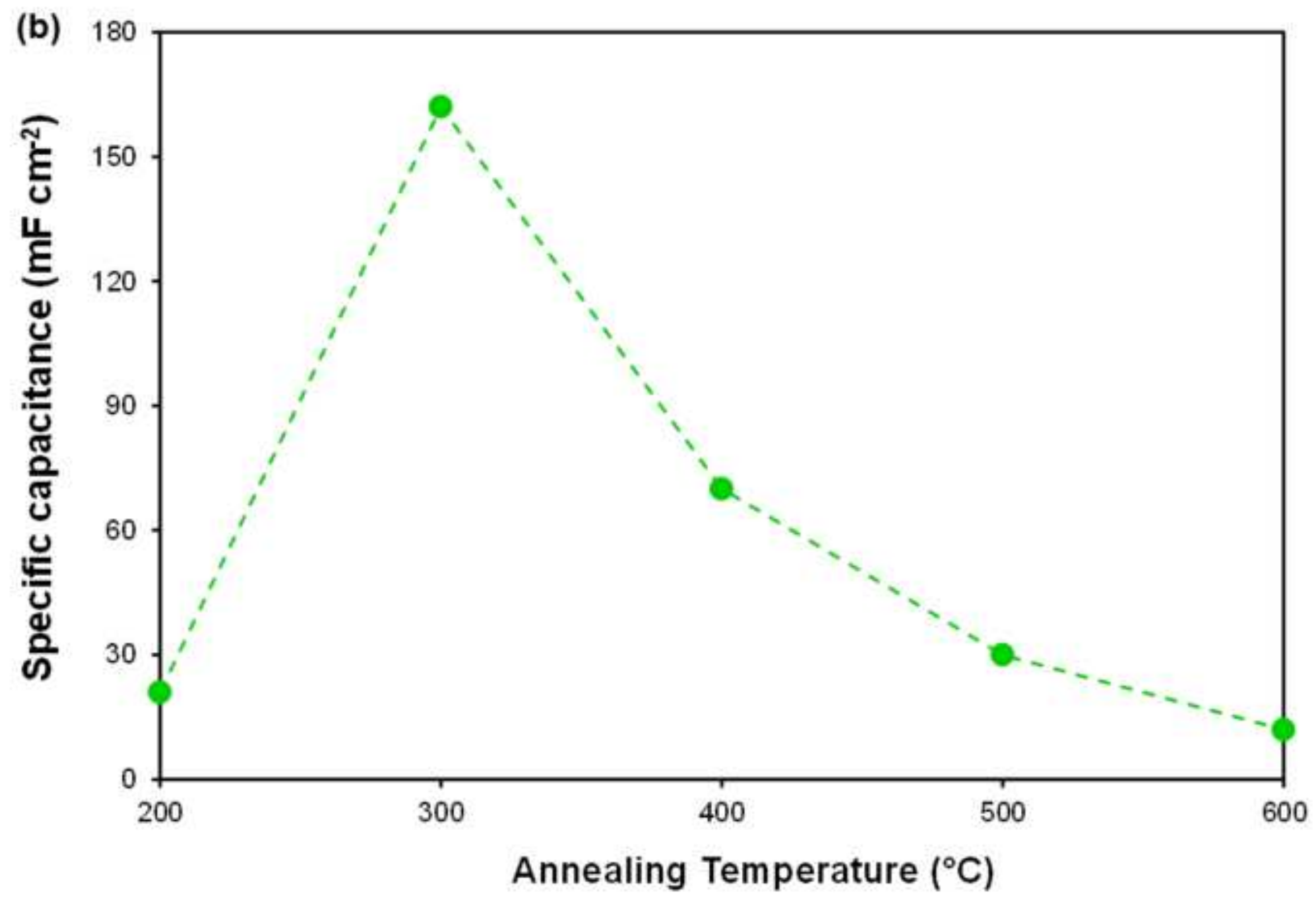




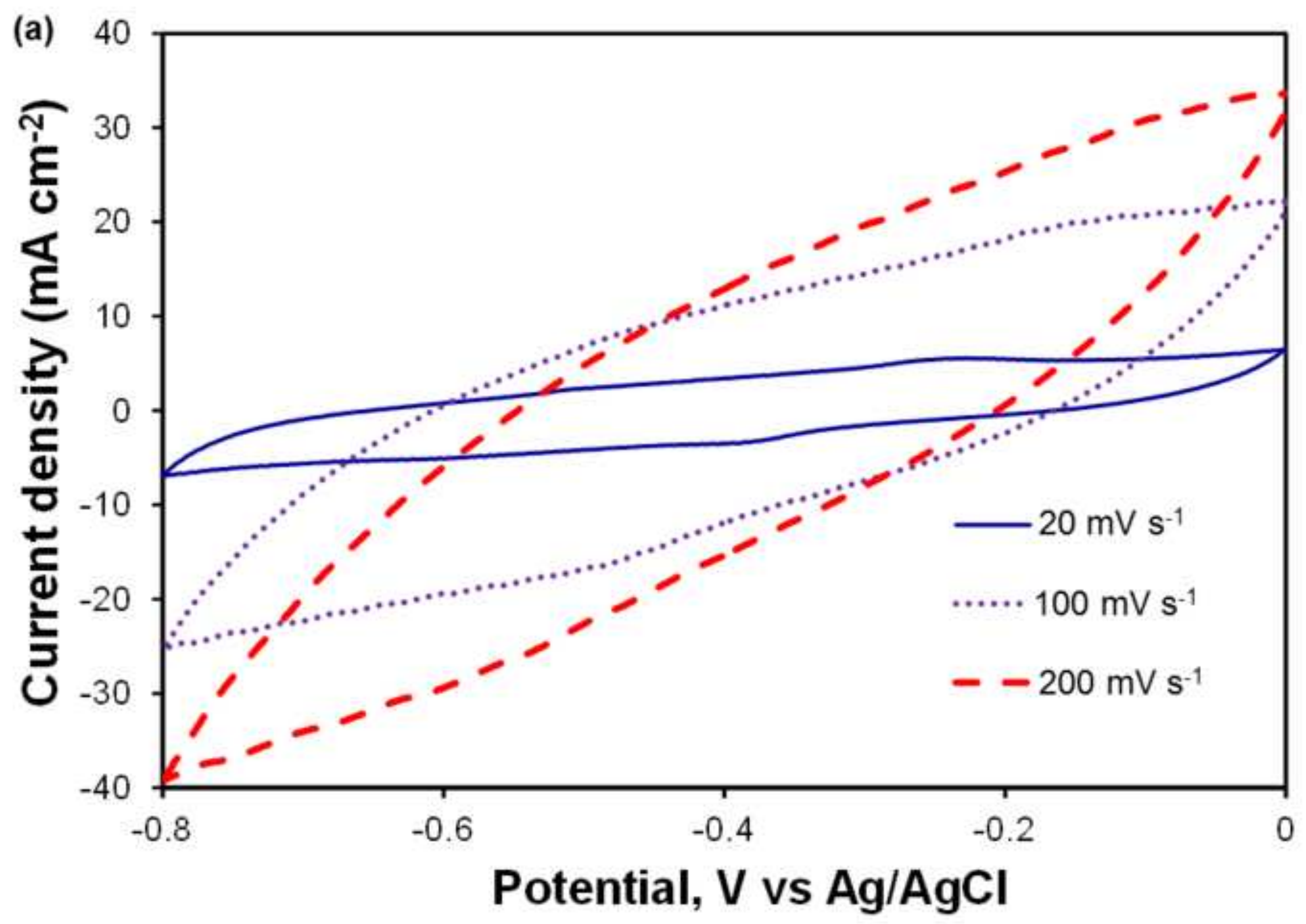




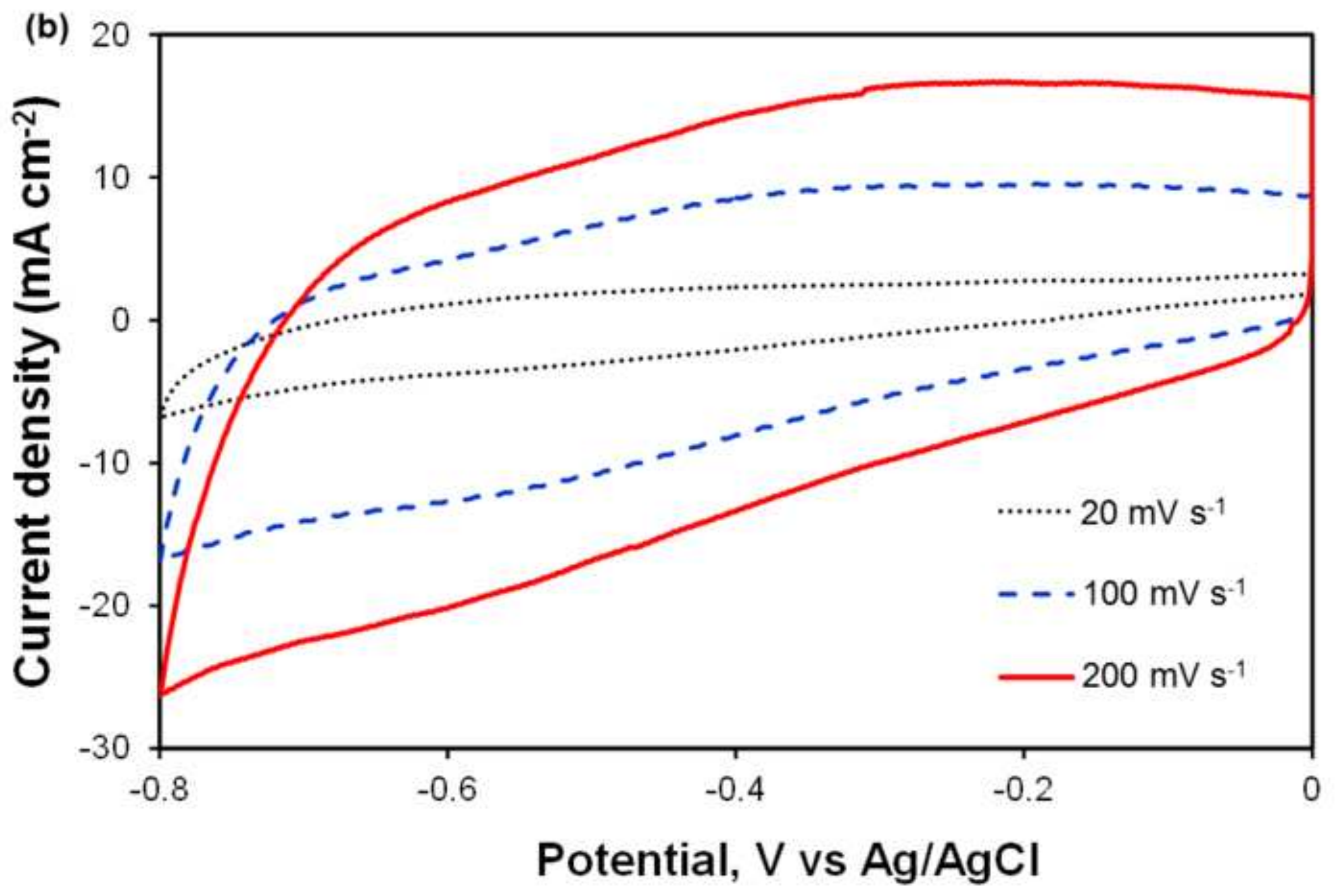




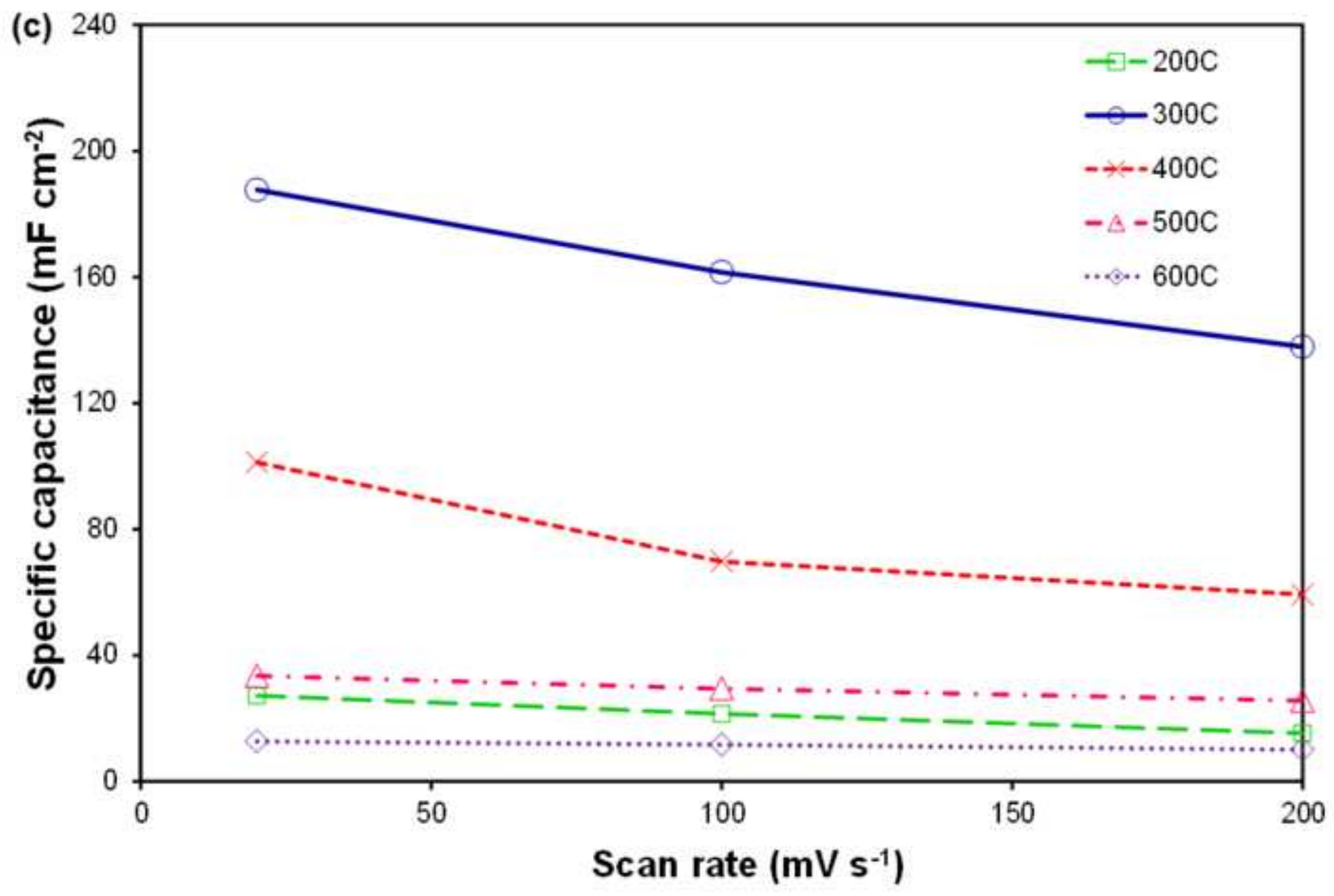




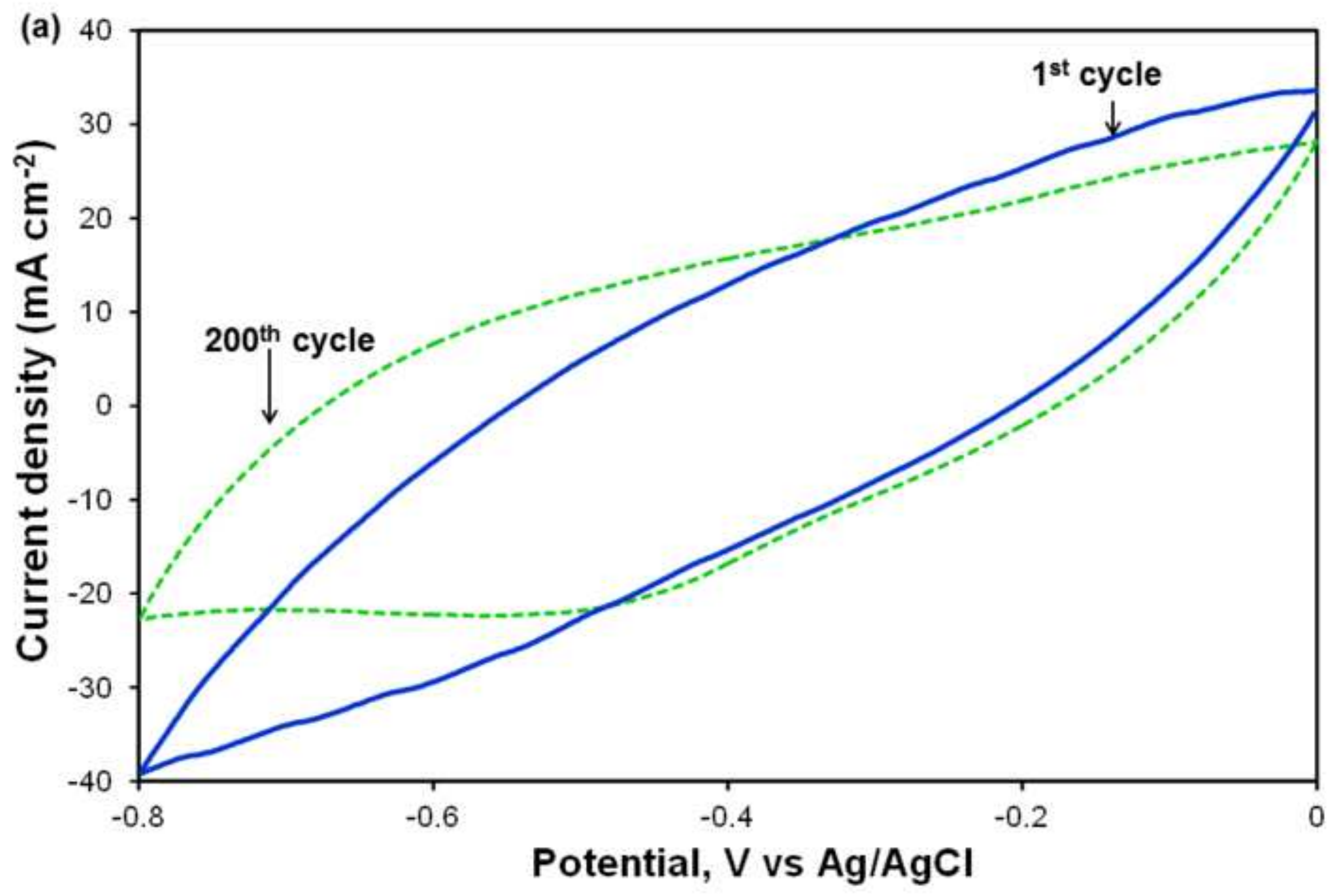




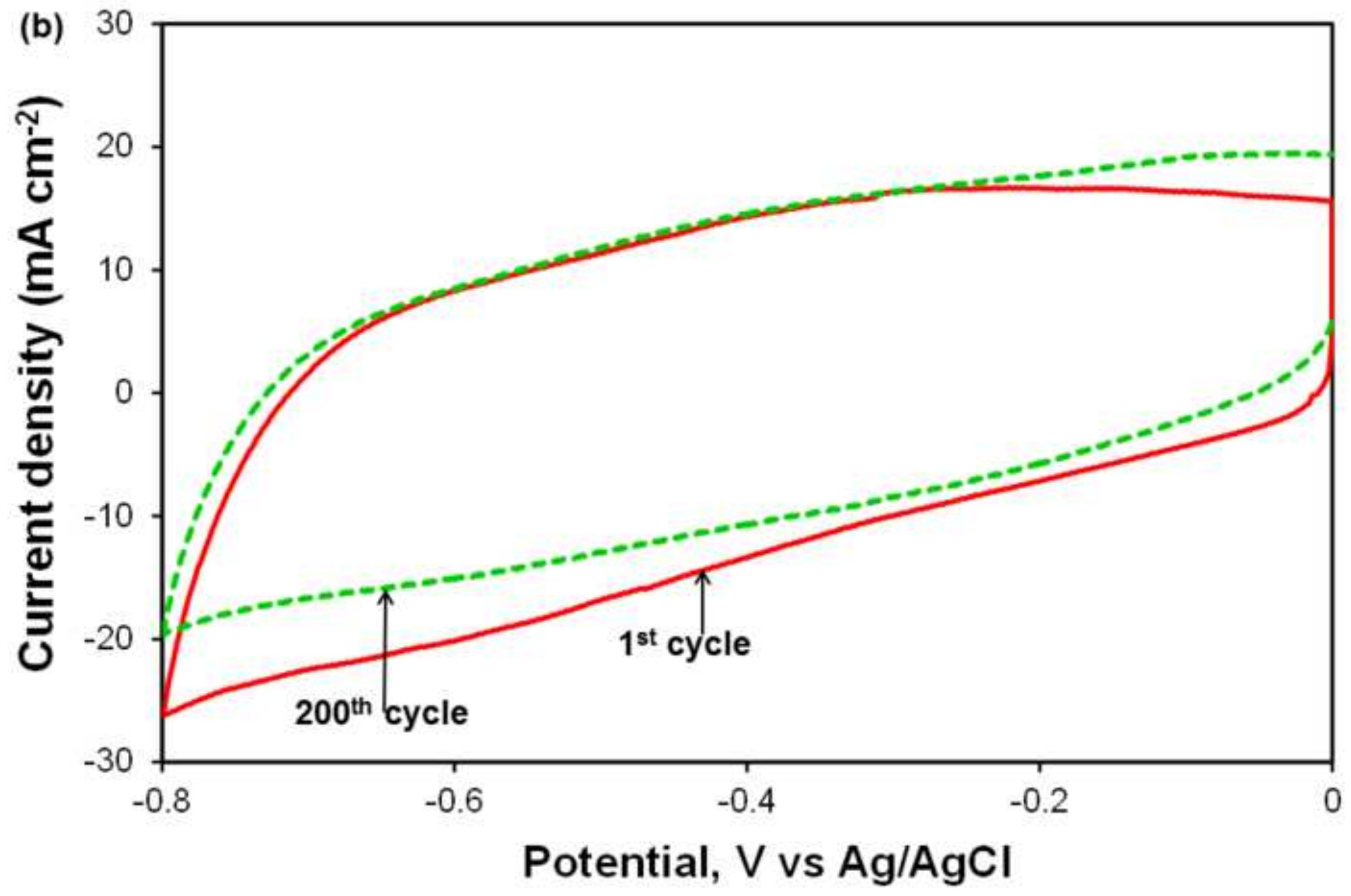




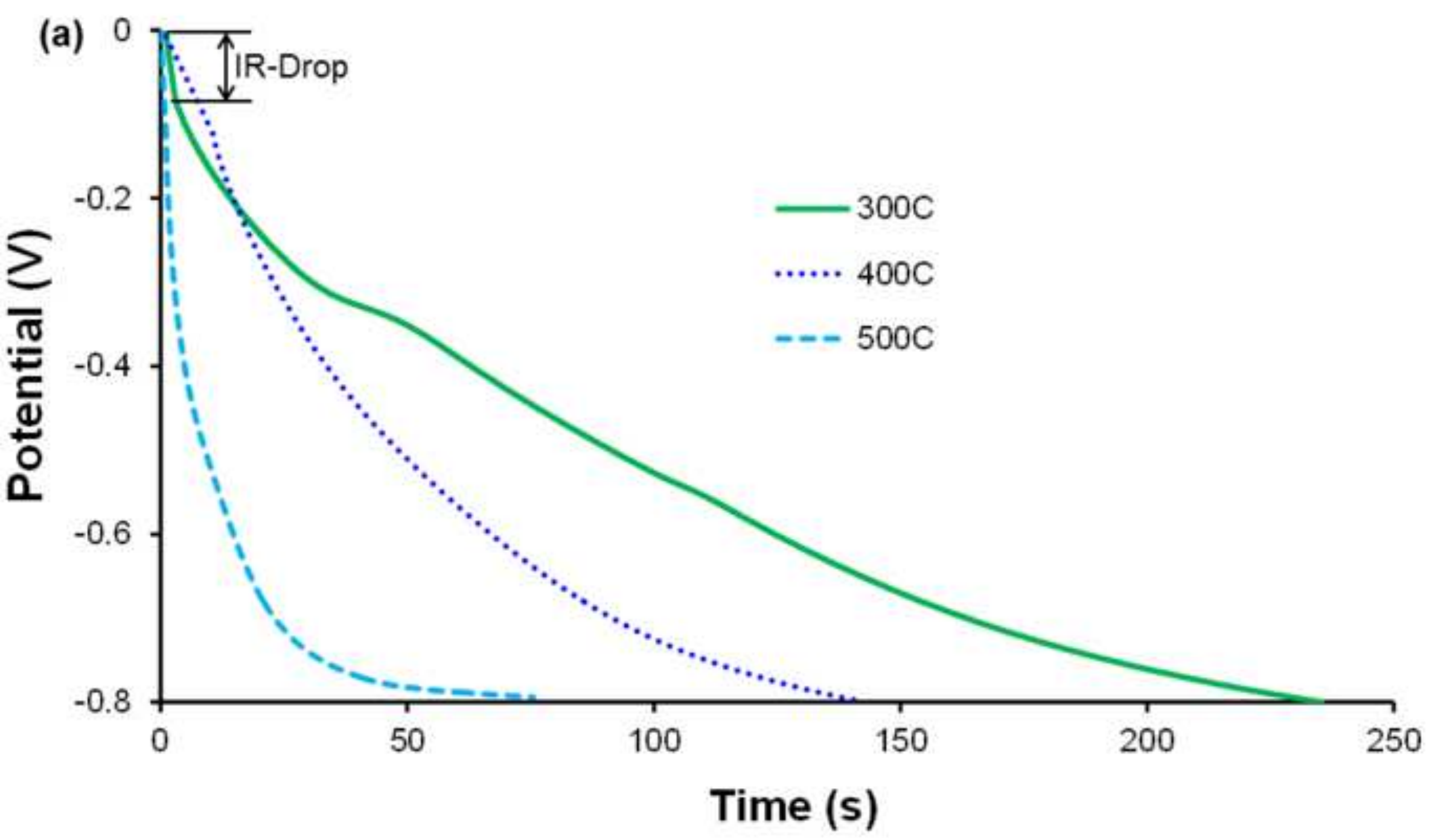




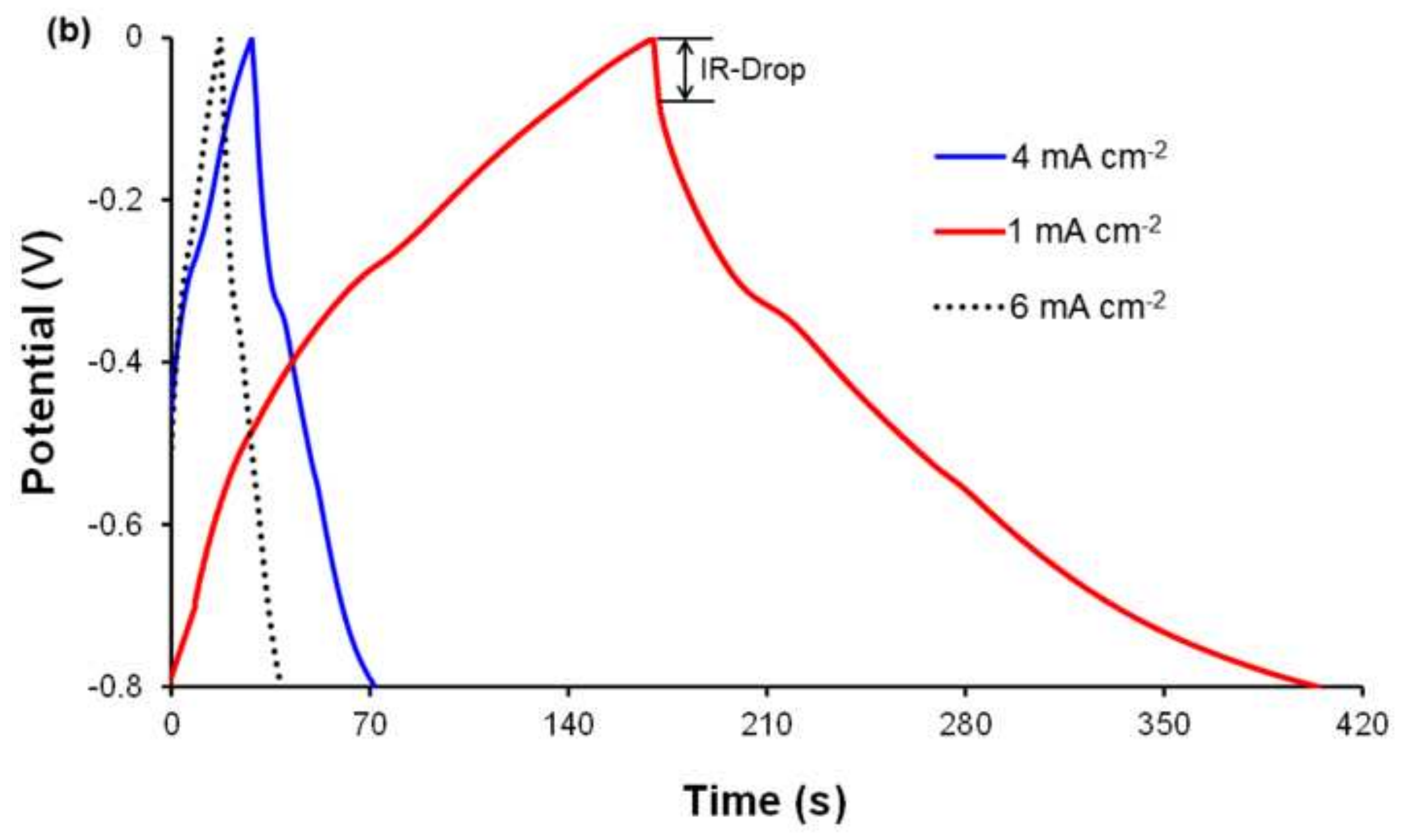




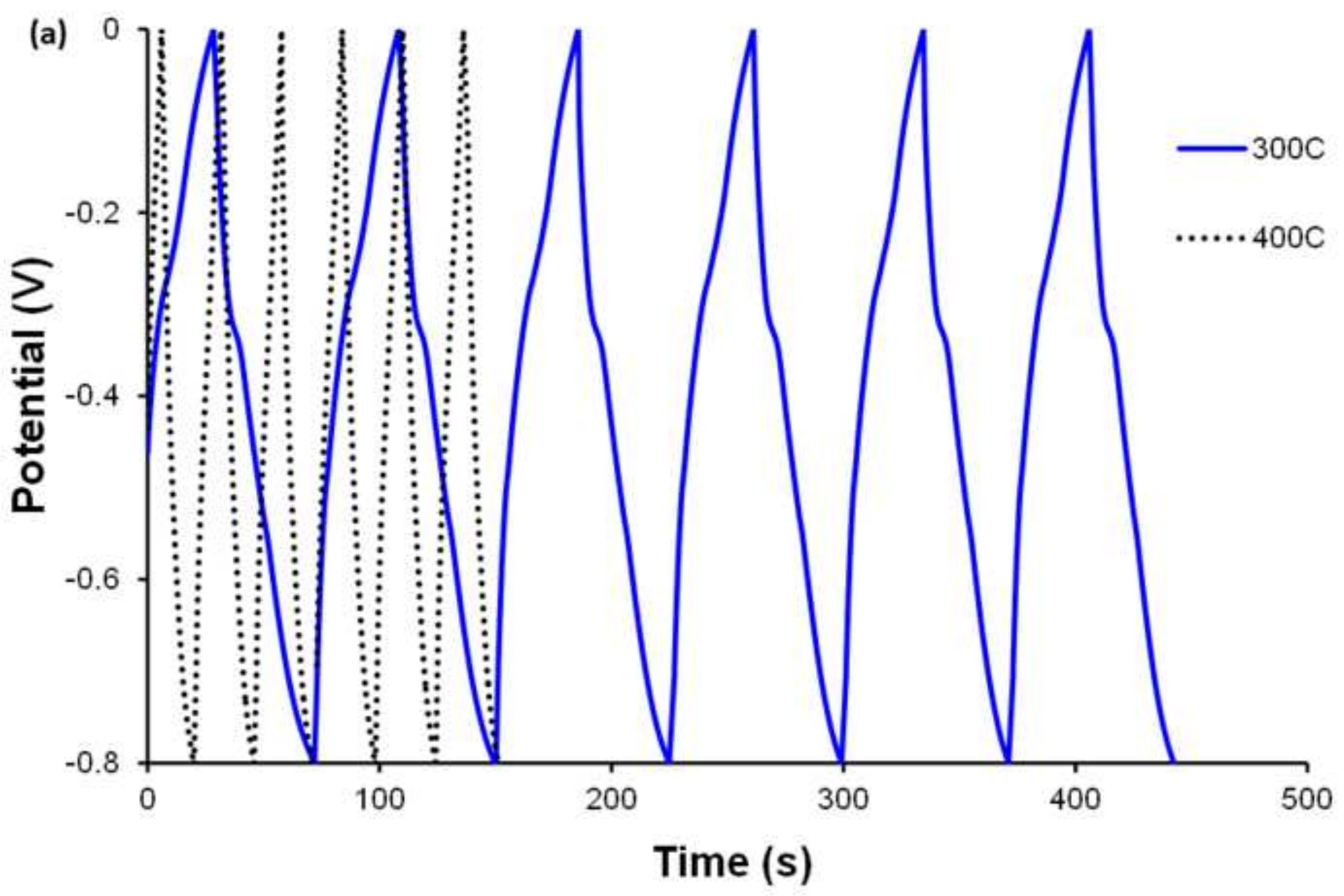




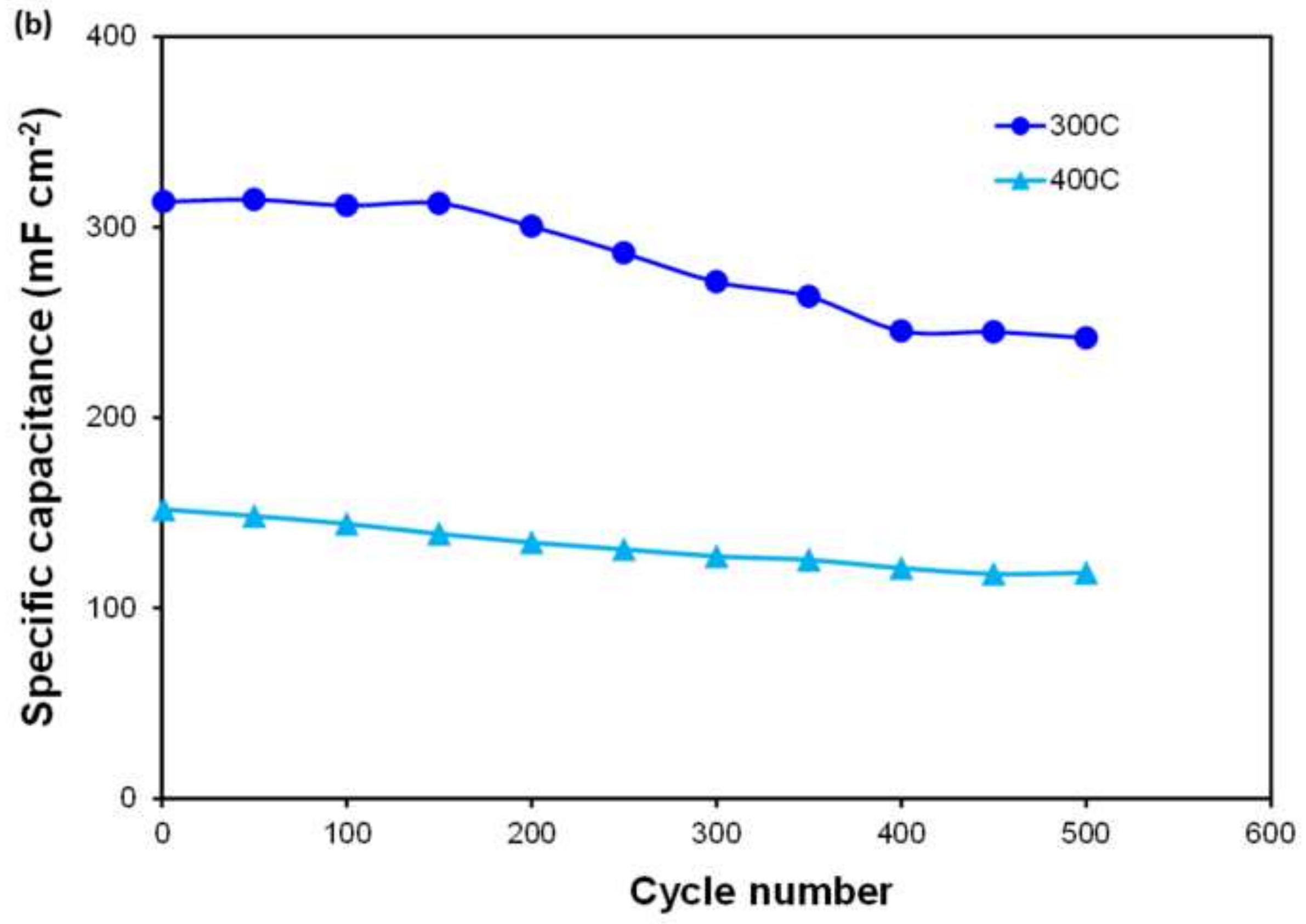




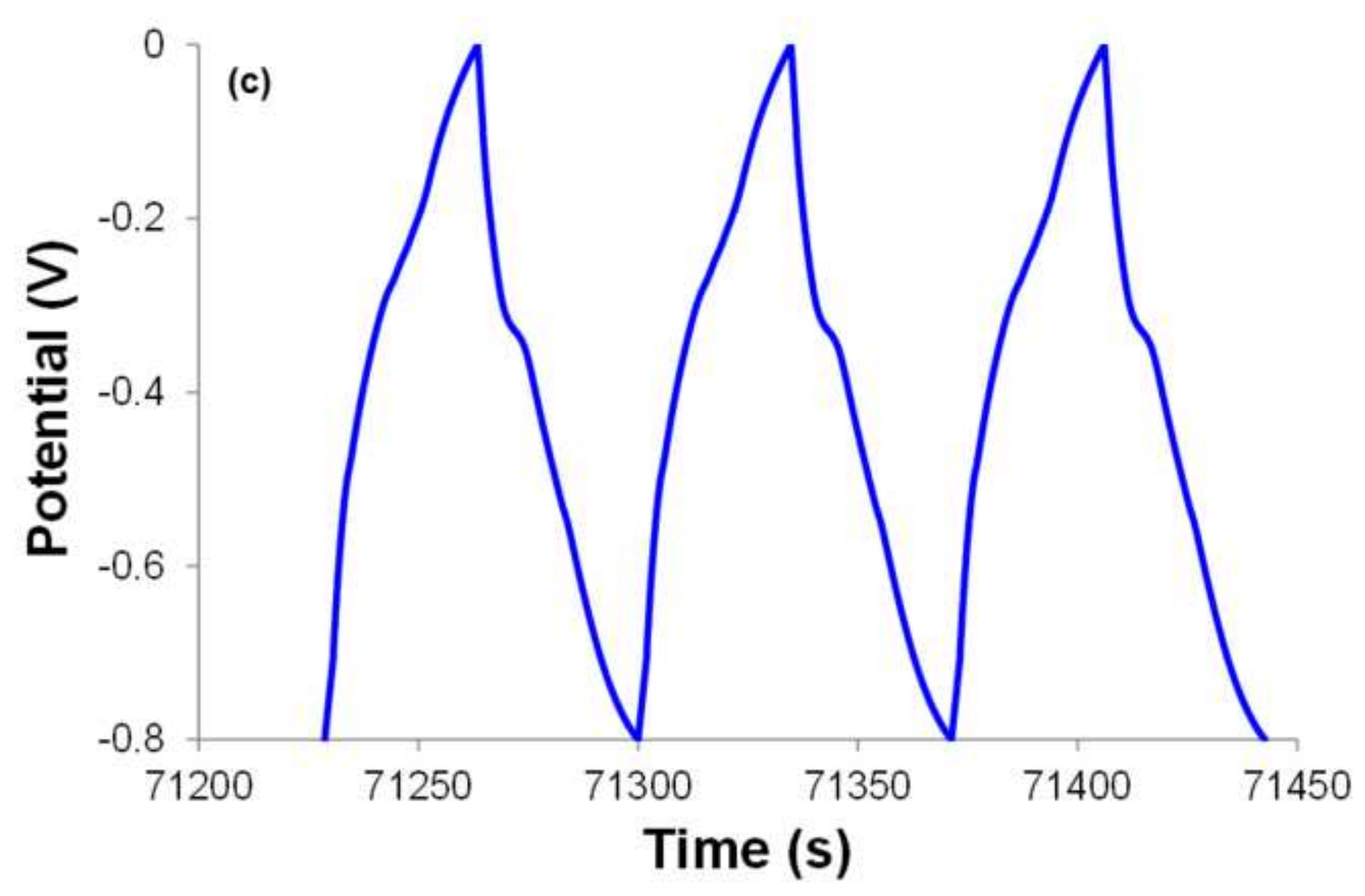




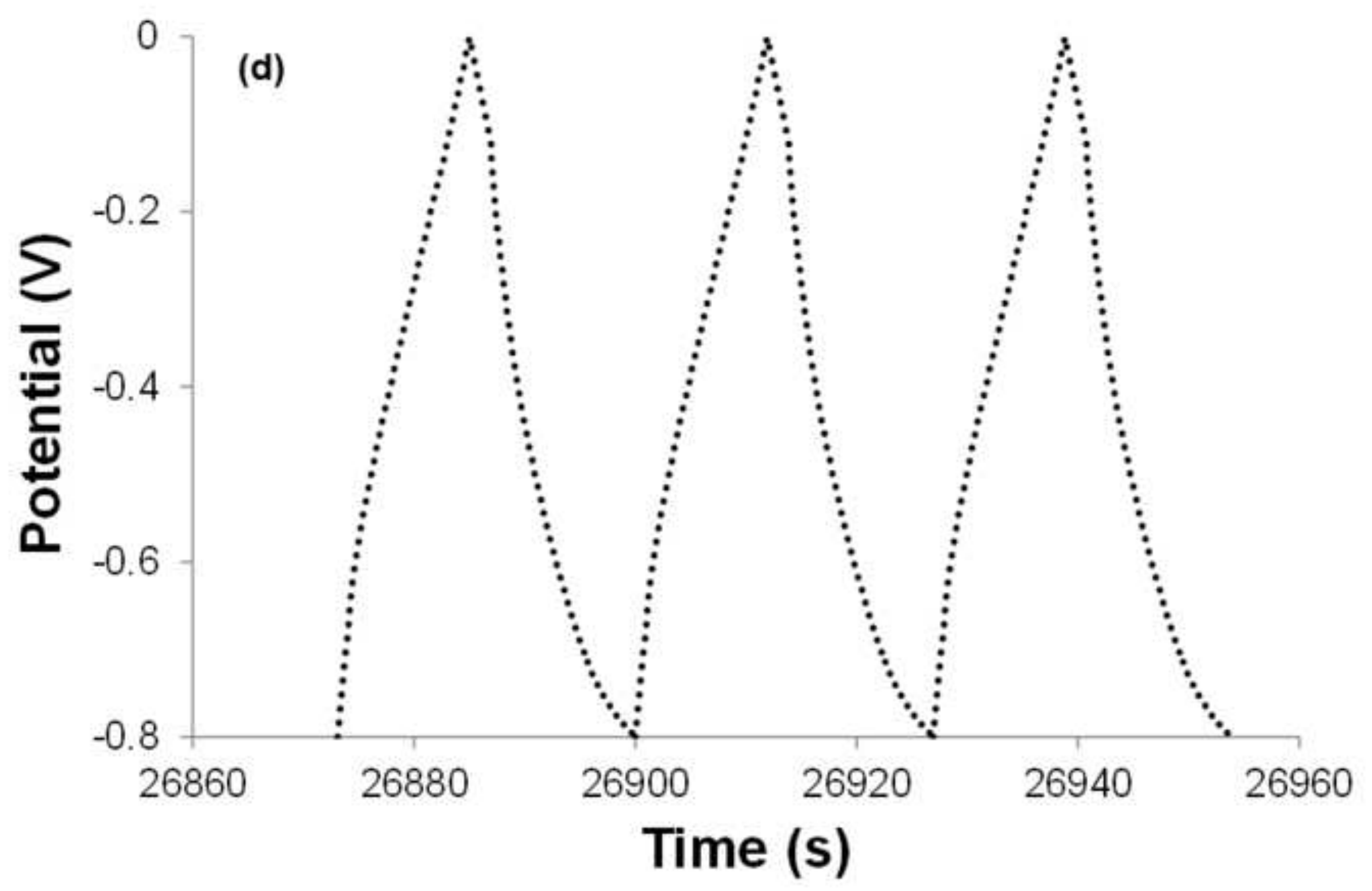




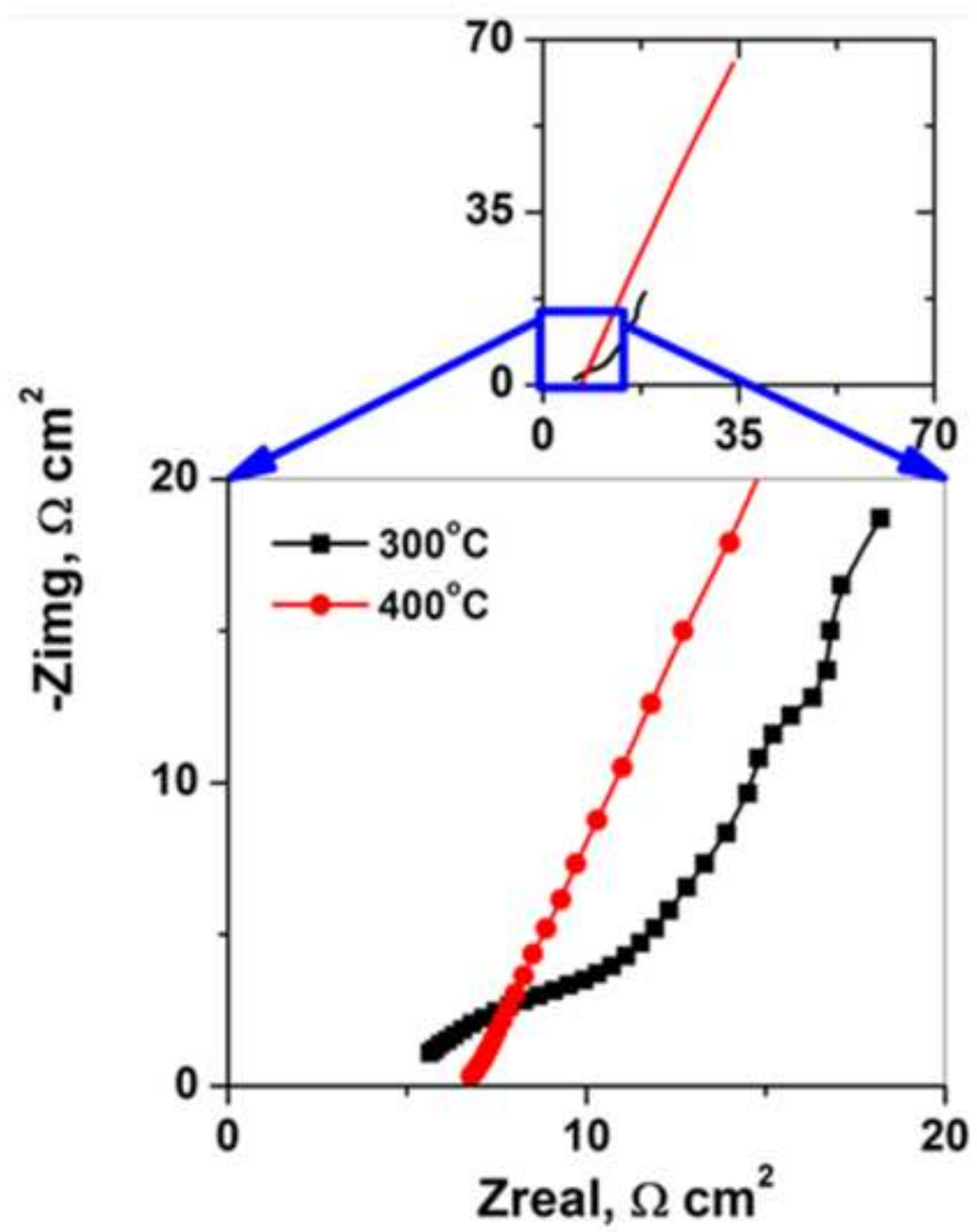

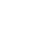




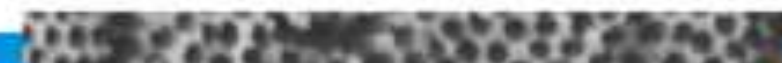

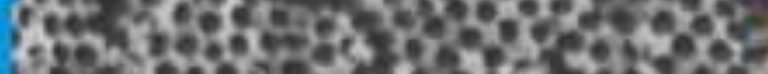

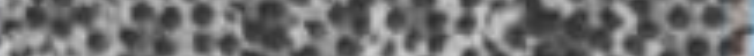

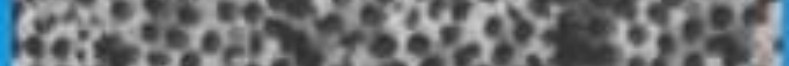

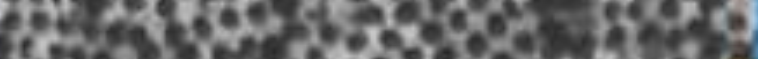

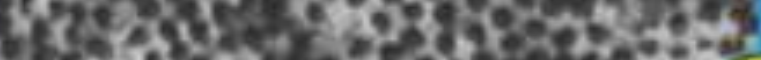

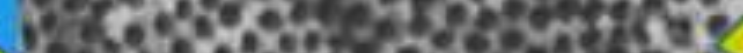

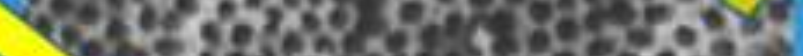

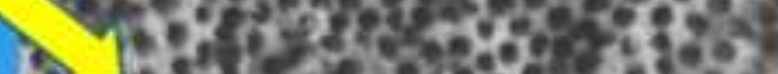

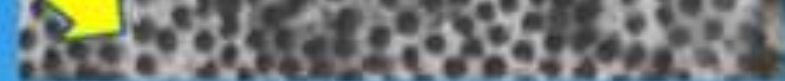
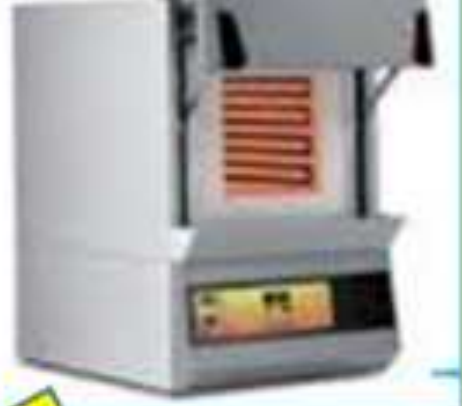

$\int_{i=0} \int_{0}$

zeise.

$20,20: 5$

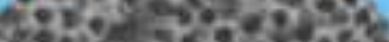

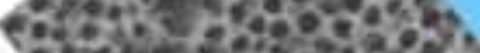

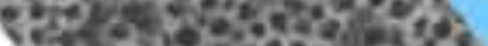

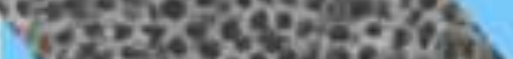

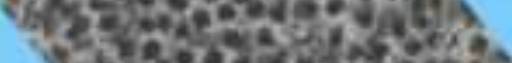

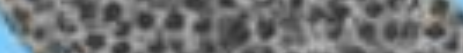

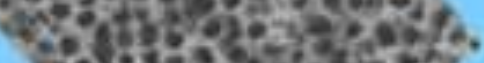

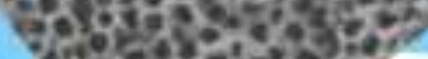

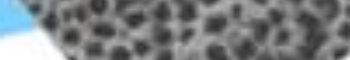

$x^{2}, 5=0$

s.

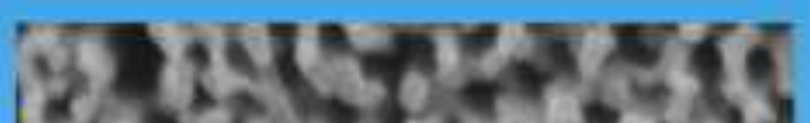

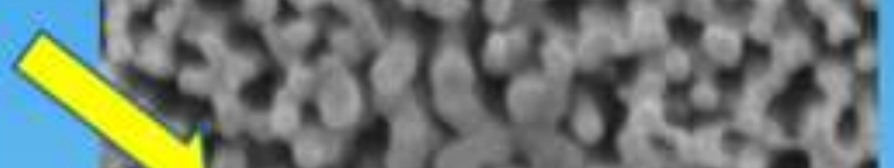

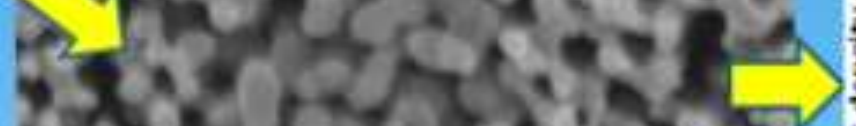

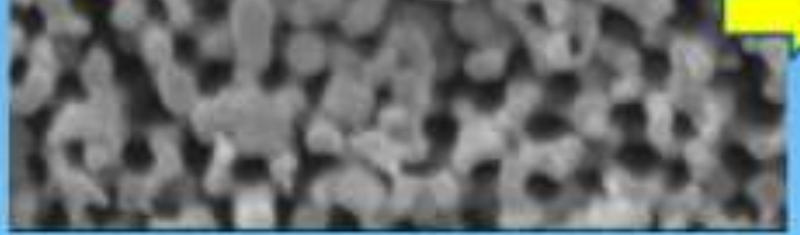
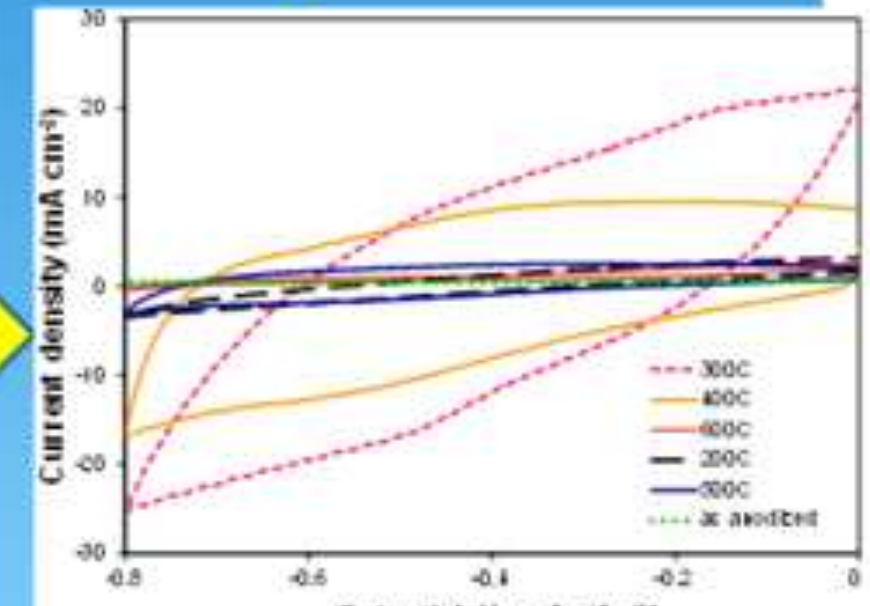

Potential, $\mathrm{V}$ vs Ag/AgCl
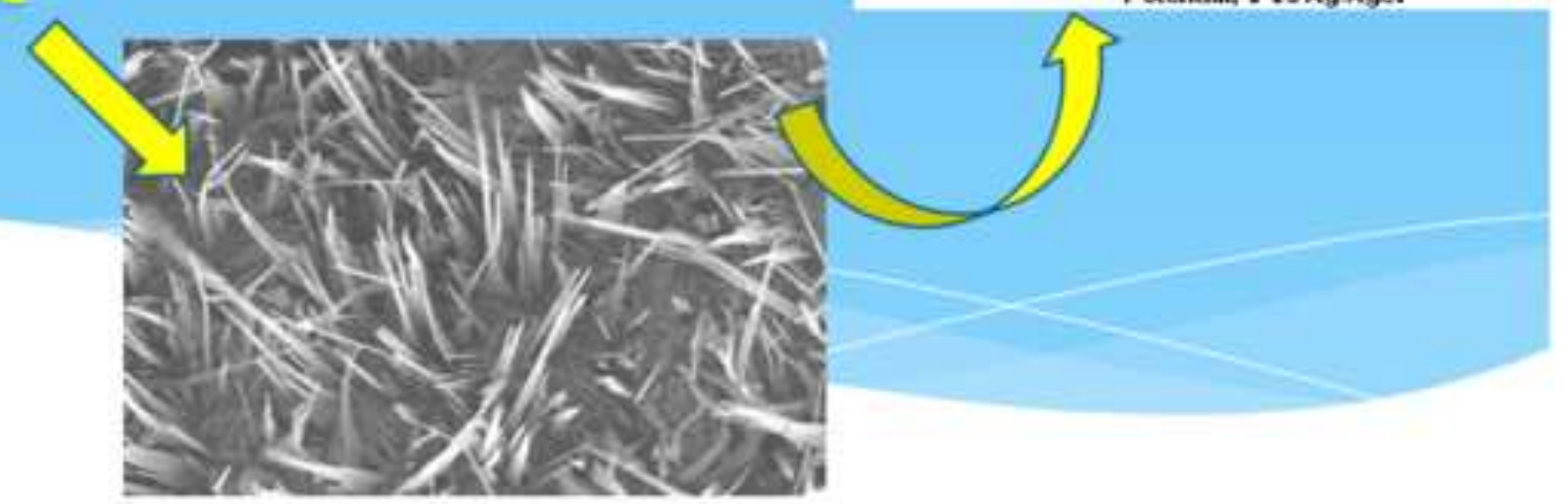